\title{
Neuroprotective Epigenetic and DNA Damage Repairing Molecular Mechanisms of L-Carnitine and its Congeners Against Aging and Age-Related Neurodegenerative Diseases
}

\author{
Article by Kumar Ponnusamy ${ }^{1}$, Siddarth Srigokul Kumar ${ }^{2}$ and Jegathambigai R Naidu ${ }^{3}$ \\ ${ }^{1}$ Department of Medical Biochemistry \& Genetics, Texila American University, George Town, \\ Guyana, South America \\ ${ }^{2}$ Vinayaka Mission's School of Medicine, Karaikal, India. \\ ${ }^{3}$ Asia Metropolitan University School of Medicine, Johor Bharu, Malaysia. \\ E-mail: gautamgkl@yhoo.com
}

\begin{abstract}
Aging is an ubiquitous biological phenomena characterized by ever-increasing susceptibility to diseases due to increased oxidative stress (OS) and an ultimate severe non-repairable membrane molecular and mitochondrial damages coupled with energy (ATP) depletion. L-Carnitine ( $\beta$-hydroxy- $\gamma$-trimethyl amino butyrate) and its congeners plays an essential role in mitochondrial ATP synthesis while being a powerful anti-inflammatory antioxidant and an organic, non-ionic bi-phasic osmolytes. L-carnitine exerts antimutagenic and genome stabilizing effects by increasing mitochondrial metabolism, anneals DNAstrand breaks and enhances genome stability by modulating histones and DNA-repairing enzymes. Poly (ADP-ribose) polymerase-1 (PARP-1) is an abundant nuclear enzyme and normally functions in DNA damage repair mechanism acts as a double-edged sword, which anneals mild repairable DNA damages, but extensive PARP-1 activation can promote cell death through processes involving energy depletion in severe OS. It has been reported that, severe oxidative stress-mediated extensive non-repairable DNA damage can over-activate PARP-1 and consumes enormous $\mathrm{NAD}^{+}$and consequently ATP, culminating in cell dysfunction or necrosis by autocatalysis of PARP-1 and caspases. The DNA damage associated with OS known to activate DNA repair proteins, including PARP-1, an important biomarker of brain aging and age-related neurodegenerative diseases. This study delineates the neuroprotective epigenetic and DNArepairing molecular mechanisms of the iron-chelating anti-inflammatory genome stabilizing antioxidant ergogenic aid L-Carnitine and its congeners against selected degenerative diseases such as Parkinson's disease (PD), Alzheimer's disease, Amyotrophic Lateral Sclerosis (ALS) and Multiple sclerosis (MS).
\end{abstract}

Keywords: Aging, Neurodegenerative diseases, Oxidative stress, DNA damage, Poly (ADP-Ribose) polymerse-1, Caspase, ATP, L-Carnitine, Iron-Chelating Anti-inflammatory Antioxidants.

\section{Introduction}

Aging is a ubiquitous biological phenomena, characterized by ever-increasing susceptibility to diseases and toxic effects of xenobiotic which leads to irreversible membrane-molecular-mitochondrial damages and ultimately death. Oxidative damage to neuronal molecules and increased accumulation of iron coupled with decreased antioxidant status in specific discrete brain areas are considered major pathological aspects of brain aging and age-related neurodegenerative diseases (NDDs) such as Parkinson's disease (PD), Alzheimer's disease (AD), Multiple sclerosis (MS), Amyotrophic lateral sclerosis (ALS) otherwise known as Motor Neuron Disease (MND) and Senile dementia (SD) and thus, special interest has been assigned to the therapeutic feature of nutritional antioxidants and iron chelators in neurodegenerative diseases. Considering the need to identify new alternatives to treat neurodegenerative diseases, this study of review delineates the neuroprotective epigenetic and DNA-damage-repair molecular mechanisms of L-carnitine 
(LC) and its congeners such as acetyl-L-carnitine (ALC) against aging and selected age-related neurodegenerative diseases.

\section{Aging, biomarkers of oxidative stress and antioxidants}

It has been documented that, malondialdehyde (MDA), nitrotyrosine, and oxo8dG/oxo8G (mainly RNA oxidation) in young and old rats support the proposition that accumulated oxidative damage to macromolecules such as lipid, protein, and nucleic acid may be a major contributor to cellular aging and the neurodegenerative diseases that accompany aging [1-11] which includes Parkinson's disease, Alzheimer's disease, Amyotrophic Lateral Sclerosis, Multiple sclerosis and Senile dementia.

Parkinson's disease (PD) is the most common neurodegenerative movement disorder that is estimated to affect approximately $1 \%$ of the population older than 65 years of age [12-13]. PD is characterized by the progressive depletion of pigmented dopamine-containing neurons in the region known as the substantia nigra pars compacta and by the presence of intraneuronal aggregates called Lewy bodies (LBs), which are enriched in filamentous $\alpha$-synuclein and other proteins that are often ubiquinated [14]. Approximately 80\% of dopaminergic neurons in the substantia nigra are already irreversibly destroyed when the symptoms of PD becomes significantly visible.

Nevertheless, currently available pharmacological therapies are unable to arrest or to reverse the progression of this relentlessly progressive and severely debilitating condition in most of the age-related neurodegenerative diseases (NDDs). PD is currently an incurable disease, and the number of subjects afflicted with this disease is constantly increasing due to the increasing global geriatric population. Therefore, the need for newer and more effective agents is receiving a great deal of attention and, consequently, being subjected to extensive research. The vast amount of information gained regarding the etiopathogenesis of PD has fuelled numerous developments and vast range of investigated agents have demonstrated immense potential for preventing and eventually providing cure for this condition. Clinical and biochemical evidences suggest that PD involves multifactorial, oxidative neurodegeneration and that L-dopa therapy aggravates the oxidative burden. Strong evidence now exists to support an aberrant role for mitochondrial functions, as well as increased oxidative stress (OS) and an ultimate severe irreversible membrane-molecular and mitochondrial damages which culminates in energy depletion and genome instability, in the pathogenesis of PD [15].

If mitochondrial defects and oxidative damage play a role in the pathogenesis of PD, then one would suspect that agents that may improve mitochondrial function or exert iron-chelating antioxidative effects could be neuroprotective. There are several agents that are currently under investigation for their potential neuroprotective effects based on their capacity to modify mitochondrial dysfunction. These include quercetin, resveratrol, astaxanthin, creatine, coenzyme Q10, nicotinamide, lipoic acid, L-carnitine and acetyl-L-carnitine, etc.

\section{Carnitine synthesis and function: L-carnitine}

Carnitine (L- $\beta$-hydroxy- $\gamma$-N-trimethylaminobutyric acid) is a vitamin-like nonprotein nutraceutical primarily biosynthesized in the liver and kidney from the amino acids lysine and methionine, ascorbic acid, vitamin $\mathrm{B}_{6}$ and niacin [16]. LC has been described as a conditionally essential nutrient for humans. Due to its chiral structure, carnitine has two stereoisomeric forms: D and L. However, only the L isomer is known to be essential for human and animal health and possess biological activity, while the other isomer is biologically inert. The main physiologic role of L-carnitine is involvement in fat and energy metabolism by mediating the transport of long-chain free fatty acids (LCFAs) across the mitochondrial membrane for $\beta$-oxidation [17] and ATP synthesis and exerts lipotrophic / lipolytic effects in a variety of cardiovascular diseases including atherosclerosis and stroke [17]. Aside from this leading task, LC supplementation has been reported to be associated with several health benefits such as regulation of carbohydrate metabolism and insulin sensitivity, mitigation of lipid peroxidation (LPo) and oxidative stress (OS), synthesis of heat shock proteins (HSPs), enhancement of the immune system and cytoprotection [18-22]. The mitochondrial antioxidant/nutrient acetyl-L-carnitine (ALC), with its iron-chelating antioxidant energizing protective 
activities and with its trophic effects, at optimal doses, can be an effective and safe prevention strategy for PD, offering the possibility of new and innovative therapeutic strategies for brain aging and several agerelated NDDs. Acetyl-L-carnitine is a highly bioavailable bi-phasic antioxidant ergogenic aid molecule, it is thought to penetrate the brain barrier better than carnitine, and it is readily converted to carnitine as needed. It is known that ALC is rapidly metabolized in human subjects, with plasma half-lives of 4.2 hours [23], which is a non-toxic conditionally essential nutrient.

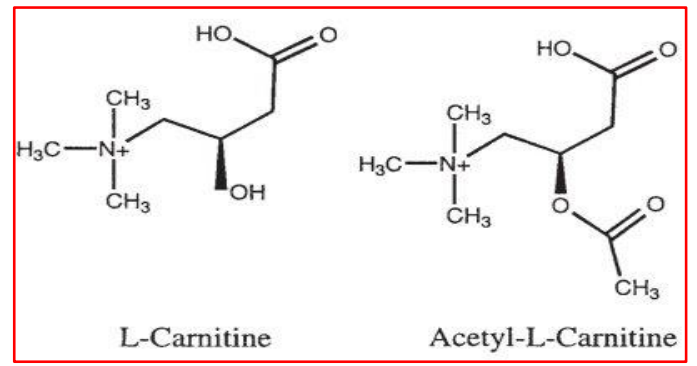

Structure of L-Carnitine and Acetyl-L-Carnitine

\section{L-Carnitine, Acetyl-L-Carnitne and Energy (ATP) Synthesis}

Acetyl-L-Carnitine (ALC) ( $\beta$-trimethyl- $\gamma$-acetylbutyrrobetaine) is the acetyl ester of carnitine that plays a key role in the transport of fatty acids from cytosol into the mitochondrial matrix of $\beta$-oxidation [24-27]. Carnitine is a cellular component with a key role in energy metabolism control. Treatment with ALC has proved to be effective in the treatment of fatigue in a variety of chronic neurological diseases [28] including dementia and in chronic fatigue syndrome [29].

\section{L-Carnitine deficiency in aging}

Experimental data demonstrate an age-associated decrease of tissue levels of L-carnitine in animals, including humans, and an associated decrease in the integrity of the mitochondrial membrane [30-32]. It has been documented that nutritional deficiency associated with carnitine precursors and iron leads to systemic carnitine deficiency. Because carnitine levels and carnitine transport decline significantly with age and the beneficial effects of acetyl-L-carnitine (ALC) supplementation on mitochondrial function have been described [33-38].

\section{Pleotropic cytoprotective effects of L-carnitine and its congeners}

\section{L-Carnitine and free radical scavenging effects}

L-Carnitine and its acyl esters such as acetyl-L-carnitine, propionyl-L-carnitine act as an oxidant either having a primary antioxidant activity (inhibiting free radical generation, scavenging the initiating free radicals, and terminating the radical propagation reactions) or, more likely, functioning as a secondary antioxidant (repairing oxidized polyunsaturated fatty acids (PUFAs) esterified in membrane phospholipids [39-40]. L-carnitine protects the cell membrane and DNA against damage induced by oxygen free radicals (OFRs) and has a pivotal role in mitochondrial $\beta$-oxidation of long-chain fatty acids (LCFAs) that increase energy supply to the cell [41] in the form of ATP. Mitochondrial dysfunction may lead to incomplete detoxification of free radicals, which may lead to oxidative damage to macromolecules such as lipids, proteins and DNA. LC has free radical-scavenging activity and the ability to scavenge superoxide anion and inhibit lipid peroxidation, thereby conferring protection against damage induced by hydrogen peroxide $\left(\mathrm{H}_{2} \mathrm{O}_{2}\right)$ [42].

\section{Antioxidant and cytoprotective efects of L-Carnitine and its congeners}

L-Carnitine has been described as a conditionally essential nutrient for humans. L-Carnitine facilitates entry of long-chain fatty acids into mitochondria for utilization as fuel and facilitates removal from 
mitochondria of short-chain and medium chain fatty acids that accumulate as a result of normal and abnormal metabolism [43]. Experimental data demonstrate an age-associated decrease of tissue levels of L-carnitine in animals, including humans, and an associated decrease in the integrity of the mitochondrial membrane [44-45].

\section{L-Carnitine and ATP and neurodegenerative diseases}

Experimental evidences suggest that acetyl-L-carnitine boosts mitochondrial ATP production and helps to protect mitochondria against free radicals (FRs). This molecule is therefore of great interest for its wide clinical application in various neurological disorders, it has beneficial effects in preventing the loss of brain function which typically occurs during aging, and its neuroprotective benefits have been observed in the hippocampus, prefrontal cortex, substantia nigra and muscarinic receptor portions of the brain. These include iron-chelating effect, antioxidant activity, improve mitochondrial energetics, stabilization of intracellular membranes and cholinergic neurotransmission [46] and modulation of caspses nd PARP-1.

\section{L-Carnitine and $\alpha$-Lipoic acid antioxidant effects}

Experimental studies indicate that $\alpha$-lipoic acid and acetyl-L-carnitine play important and potentially synergistic roles in normal mitochondrial function, and that reduced levels of these compounds are associated with increased mitochondrial oxidant production [47-49]. L-Carnitine also has an ability to reduce production of oxygen free radicals (OFRs) [50]. The effects of $\alpha$-lipoic acid and acetyl-L-carnitine on oxidative stress (OS) that contributes to the pathogenesis and cardiovascular complications of hypertension suggest that these compounds may be useful adjuncts in treatment [51] and enhances overall antioxidant status of cells.

\section{Genome stabilizing and anti-mutagenic effects of L-Carnitine and Acetyl-L-Carnitine}

Previous study demonstrated that, improvement in sperm chromatin quality was demonstrated by oral intake of some antioxidant agents such as L-carnitine [52]. L-carnitine and ALC, as antioxidant [53], may protect sperm plasma membrane with high level of unsaturated fatty acid content [54]. L-carnitine and LAC act as buffering system to adjust acetyl-CoA concentration [54]. ALC is considered as donor of acetyl group and can transfer its acetyl group to histone by acetyl transferase enzyme and by this way it can improve protamination [55]. It has been documented that, both L-carnitine and acetyl-L-carnitine enhances the chromatin quality and hence genome stability by annealing the DNA single strand breaks (DNA-SSBs) in human peripheral blood smears by augmenting the activity of the DNA repair enzyme poly (ADP-ribose) polymerase-1 (PARP-1) and cellular ATP levels [56]. Further L-carnitine ameliorates and repairs the DNAstrand breaks induced by the genotoxic agents such as acrylamide [57], exerts antimutagenic and genome stabilizing effects and cytoprotective anti-apoptotic effects.

\section{L-Carnitine and GSH}

Acetyl-L-Carnitine (ALC) is a small water-soluble peptide located in the mitochondria. It contains a carnitine moiety which is important for the oxidation of fatty acids and an acetyl moiety which is involved in maintenance of acetyl-CoA levels and can promote the production of the antioxidant glutathione [58-60] and acetylcholine.

\section{Anti-inflammatory and neuroprotective effects of L-Carnitine}

Acetyl L-carnitine has multiple roles in neuro-protection. ALC readily crosses the blood-brain barrier, where it stabilizes cell membranes, acts as an effective antioxidant and protects brain. CRP is a positive acute phase protein that is increased in inflammation. Inflammatory stimuli cause the release of cytokines like interleukin (IL-1), IL-6 and tumour necrosis factor- $\alpha$ (TNF- $\alpha$ ), and these cytokines increase the synthesis and release of CRP [61]. CRP nd IL-6 levels may be decreased with carnitine treatment. There are a few reports supporting the hypothesis that treatment with L-carnitine has improved the chronic inflammation in haemodialysis patients in recent years [62-63]. L-carnitine was reported to down-regulate 
cytokines such as IL-1, IL-6 and TNF- $\alpha$ and/or increase clearance of these cytokines in knee osteoarthritis [64] and a variety of inflammatory disorders.

\section{Iron-chelating antioxidant and chromatin stabilizing effects of $L$-Carnitine and its congeners}

ALC inhibits lipid peroxidation and xanthine oxidase activity in rat skeletal muscle [65]. ALC reduces lipid peroxidation and lipofuscin concentration in aged rat brain [66]. ALC also inhibits oxidant-induced DNA single-strand breaks (DNA-SSBs) [67]. ALC may possess a direct antioxidant activity as demonstrated in vivo [68-69]. Related compounds, such as L-propionyl L-carnitine and L-carnitine (LPC), have been shown to have antioxidant activity by chelating metals, and inhibiting the age-associated increase in lipid peroxidation [70-71]. An antioxidant role of L-propionyl L-carnitine has also been implicated in ischemia-reperfusion injury. L-Carnitine in rats prevented doxorubicin cardiotoxicity as monitored by echocardiography, release of myosin light chain-1, and aldehydic lipid peroxidation products [72]. ALC prevented oxygen radical-induced cell death in human diploid fibroblast cell lines, which was explained as due to increasing the activity of antioxidant enzymes and sustaining the activity of mitochondrial complex I-NADH ubiquinone reductase and complex IV-cytochrome oxidase of the electron transport chain [73]. In addition, ALC protected mitochondrial complex III ubiquinol cytochrome $c$ reductase, perhaps as an iron chelator [74].

\section{L-Carnitine and antiapoptotic effects}

It has been documented that, L-carntine and its congeners exerts antiapoptotic effect in various pathological conditions. The anti-apoptotic effect of LC also has been demonstrated in human lymphoma cells treated with apoptosis-inducing agents [75]. The chemotherapeutic ejects of L-carnitine have already been demonstrated in AIDS and Alzheimer's disease and ischemic injury [76-78]. Apoptosis has been implicated in the etiology of several human diseases, including Alzheimer's, AIDS [77] and ischemic injury [78-79]. Interestingly, a number of studies and clinical trials have shown that L-carnitine has therapeutic effects in these conditions [80-82].

\section{Cytoprotective effects of L-Carnitine and its congeners in aging and age-related neurodegenerative diseases}

\section{Effects of L-Carnitine and its congeners in vascular functions}

L-Carnitine and its congeners are bi-phasic antioxidants exerts a versatile cytoprotective effects against aging and age-related neurodegenerative diseases. Recent experimental studies have shown that administration of $\alpha$-lipoic acid and/or acetyl-L-carnitine can reduce oxidant production and improve mitochondrial function in models of aging [83-84]. Furthermore, these compounds reduce blood pressure (BP) and improve endothelial function in animal models of hypertension [85-86]. Experimental studies have consistently demonstrated an antihypertensive effect of $\alpha$-lipoic acid or L-carnitine in various rat models of hypertension, including spontaneously hypertensive rats [87-88]. L-carnitine improves vascular functions and in diabetes [89-90]. L-Carnitine and its congeners exerts hypolipidemic and vasodilatory effects [92-93]. A prior study demonstrated a decrease in systolic BP and a direct vasodilator effect in nailfold capillaries after treatment with oral L-carnitine ( $3 \mathrm{~g} / \mathrm{d}$ for 20 days) in patients with digital vasospastic disease [94]. Intravenous administration of L-carnitine (3-g bolus) enhanced reactive hyperemia in patients with peripheral arterial disease [95].

\section{Acetyl-L-Carnitine and anti-aging effects}

ALC, like L-carnitine, is present in high concentration in the brain as well as muscle, and provides acetyl equivalents for the production of the neurotransmitter acetylcholine [96-98]. ALC has been shown to delay or reverse age-related deficits in mitochondrial function, such as in the heart and liver [99-104]. In addition, ALC improves age-associated cognitive dysfunction and neurodegeneration in animals [105-110] and in Alzheimer's patients, [111-112] as well as decreases oxidative stress [113-114]. 
Texila International Journal of Basic Medical Science

Volume 2, Issue 1, Jul 2017

\section{Acetyl-L-Carnitine, Nerve growth factor receptor synthesis and brain injury}

ALC has been shown to enhance the response of PC12 cells to NGF by stimulating the synthesis of NGF receptors [115-117]. ALC and Brain Injury: Administration of ALC and N-acetyl-cysteine during the first 24 hours has also been shown to reduce the volume of lesion after traumatic brain injury [118-120] and edema. Both antioxidants have in addition been tested as early neuroprotective treatments after ischemic spinal cord injury and provide significant reduction of motor dysfunction [121-123] after stroke.

\section{Acetyl-L-Carnitine and blood brain barrier damage}

ALC is a naturally occurring conditionally essential membrane stabilizing antioxidant [124] and is synthesized in the human brain, liver, and kidney by the enzyme ALC-transferase [125]. Oxidative damage of the endothelium disrupts the integrity of the blood-brain barrier (BBB). Methamphetamine (METH) has been consistently reported to increase blood brain barrier (BBB) permeability through oxidative stress, both in vivo and in vitro, as a result of tight junction and cytoskeleton disarrangement. Acetyl-L-carnitine, a natural occurring compound, prevents BBB structural loss in a context of METH exposure, and reasoned that ALC could also preserve the acetylation of microtubules under METH action [126]. Alcohol exposure increases the levels of reactive oxygen species (ROS; superoxide and hydroxyl radical) and nitric oxide radical (NO') the endothelium derived relaxing factor (EDRF) in brain endothelial cells by activating NADPH oxidase and inducible nitric oxide synthase (iNOS). Alcohol inhibits glucose transport across the blood-brain barrier (BBB), leading to BBB dysfunction and neurodegeneration. Administration of acetylL-carnitine (a neurotrophic and/or neuroprotective iron-chelating antioxidant ergogenic aid membrane stabilizing antioxidant) significantly prevents the adverse effects of alcohol on glucose uptake, BBB damage and neuronal degeneration [127]. Oxidative damage to mitochondrial membrane proteins, and decreased membrane potential and an ultimate mitochondrial injury and destabilization of superoxide dismutase (SOD) are the cascade of events caused by ethanol toxicity, which are ameliorated by ALC, through its free radical (FR) scavenging, membrane-stabilizing effects on BBB and vasodilatory effects [128] through prostacyclin ( $\mathrm{PGI}_{2}$ ) synthesis. As ALC acts as a precursor of the acetylcholine and can cross the blood-brain barrier more efficiently than L-carnitine, it has been widely used in animal and human studies [129-130]. ALC has been shown to be beneficial in treating Alzheimer's disease (AD) [131], Parkinson's disease (PD), Amyotrophic Lateral Sclerosis (LS), Multiplesclerosis (MS) and Senile dementia (SD). L-carnitine and ALC is considered to be safe and without significant side effects [132].

\section{Poly (ADP-Ribose) Polymerase-1(PARP-1)}

PAR and PARPs have been most studied in the DNA damage response. PARP-1, the most abundant family member, is activated by direct binding to DNA-strand breaks [131], increasing PARP-1 activity 10to 500-fold [132]. Activation leads to modification of PARP-1 itself and other proteins in the DNA-damage repair pathway [132]. It has been hypothesized that excessive DNA damage leads to PARP-1-dependent cell death via necrosis [133], whereas PARP-1 is cleaved and inactivated early in apoptosis [134].

DNA damage response signaling is known to be involved in the production of pro-inflammatory signals from damaged cells [135]. Unrepaired DNA damage can also trigger apoptosis generating many new DNA strand breaks through activation of caspase activated DNase nuclease [136]. PARP-1 itself is cleaved early during apoptosis [137] for unknown reasons, however one can delineate that, in case of severe oxidative stress, DNA under goes an irreversible severe damage coupled with ATP depletion, and hence PARP-1 acts as a double-edged sword like action and triggers a cascade of events towards apoptoic cell death through autolytic cleavage of PARP-1 and activtion of caspases.

\section{L-Carnitine and inhibition of caspases}

Apoptosis is a form of cell death which is mediated by a group of highly specific cysteine proteases known as cysteine aspartic acid specific proteases (caspases). Palmitoyl-L-carnitine (PLC) has been shown to activate the pro-apoptotic caspases [138]. It has been shown that palmitoyl-carnitine reversed the 
inhibition of caspase activity by L-Carnitine [139]. It has been suggested that L-carnitine reduces apoptosis through inhibition of caspase activation [140].

Other in vitro investigations strongly supported that L-carnitine able to inhibit the death planned, most likely by preventing sphingomyelin breakdown and consequent ceramide synthesis [141]. Furuno et al. [142] suggested that the protective effect of L-carnitine on cellular apoptosis could be explained by inhibition of mitochondrial permeability transition and its ability to remove toxic LCFAs through the formation of dissociable complexes [143].

\section{L-Carnitine, caspases and apoptosis}

L-Carnitine (LC) was also able to inhibit proteolytic activation of caspase 9 mediated by cytochrome $\mathrm{c}(\mathrm{Cyt}-\mathrm{c})$ and ATP [144-145]. Vescovo et al. speculated the below mechanisms for anti-apoptotic effects of LC: Blocking of tumor necrosis factor-alpha (TNF- $\alpha$ ) and sphingolipids activation cascade, inhibiting the cleavage of caspases substrates at mitochondrial level, making it a general caspase inhibitor [146]. Moreover, it has been shown that LC prevents doxorubicin-induced apoptosis in cardiac myocytes, by inhibiting the doxorubicin-induced sphingomyelin hydrolysis and ceramide generation [147]. However, there are recent observations that LC, beyond the well-known metabolic effect, possesses some more complex activities in regulating gene expression and activity of caspases, the activation of which represents the compulsory step for cell death execution [148]. L-carnitine is able to stabilize mitochondrial membranes and increase the supply of energy in the form of ATP to the organelle and protect the cell from apoptotic death [149].

\section{Antiapoptotic and genome stabilizing effects of L-carnitine and its congeners}

DNA damage due oxidative stress and unrepaired DNA strand breaks and several defects in DNAdamage repair genes are associated with aging and age-related diseases. Increased DNA- single strand breaks (DNA-SSBs) and apoptosis was observed in the cells of the aged animals. An increase in DNA damage and mutations in the lymphocytes of aged humans was attributed to a decline in the efficacy of the repair of ROS-induced DNA damage with age. It has been documented that, L-carnitine reduces lymphocyte apoptosis and oxidant stress in HIV-1-infected subjects treated with zidovudine and didanosine [150]. L-Carnitine and its derivatives interacts in the molecular level and anneals the DNA-single strand breaks (DNA-SSBs) induced by xenibiotics [151] and age-related mitochondrial DNA deletions [152] by increasing the DNA-damage repair enzyme, poly (ADP)-ribose polymerase-1 [153], prevents apoptosis and alters gene expressions [154-156]. L-carnitine and its derivatives increases cytochrome oxidase subunits [157] and enhances age-related reduction of mitochondrial DNA transcription [158]. Carnitine exerts sparing effect on protein, lysine, vitamin $\mathrm{C}$, methionine, thiol, reduced glutathione (GSH) and creatine phosphate (CP) [159] and augments ATP synthesis by mitochondrial metabolism. Previous study documented that, L-carnitine supplementation reduced oxidative DNA damage in peripheral blood lymphocytes (PBLs) of maintenance hemodialysis patients with HCV infection [160]. It is reported that, administration of L-carnitine prevents and anneals the oxidative DNA damage induced by free radicals in the different discrete brain areas of aged rats [161] and L-Carnitine as well as acetyl-L-carnitine caused a decrease in DNA-single strand breaks in human peripheral blood lymphocytes subjected to hypoxanthine treatment possibly by accelerating the DNA-damage repair enzyme poly (ADP ribosyl) polymerase- 1 and also other related repair mechanisms [151]. The decrease in DNA-single strand breaks and apoptosis in basal conditions and after $\mathrm{H}_{2} \mathrm{O}_{2}$ exposure in the L-carnitine treated aged animals could be attributed to the antiapoptotic role of carnitine which was well demonstrated in earlier studies under other conditions [162]. The protective role of L-carnitine could also be attributed to its antioxidant role as observed by [163-164] Rani and Panneerselvam 2002 and Gulcin 2006 and thereby this could have contributed to its protective role on DNA. Chang et al. (2002) reported that cisplatin-induced mitochondrial DNA (mtDNA) damageinjury in the kidney and small intestine was strongly inhibited by L-carnitine [165].

Acetyl-L-carnitine has also been shown to improve lipid, oxygen and glucose delivery for enhanced energy metabolism and generation of ATP [166]. In addition, acetyl-L-carnitine could involve a restoration 
of mitochondrial function and/or improved use of energy from glycolysis in cultured neuroblastoma cells treated with the neurotoxin, 1-methyl-4-phenyl tetrahydropyridine (MPTP) [167]. The free radical scavenger activity of acetyl-L-carnitine might justify its protective effect. Moreover, L-carnitine improves the transcription of mtDNA probably by increasing oxygen consumption and therefore ATP synthesis; this energy is required for DNA repair. Furthermore, acetyl-L-carnitine enhances the activity of DNA repairing enzyme, poly (ADP-ribosyl) polymerase-1 [168].

L-propionyl-carnitine (LPC) showed a dose dependent free radical scavenging activity. In fact, it was able to scavenge superoxide anion, to inhibit the lipoperoxidation (LPo) of linoleic acid, and to protect DNA from cleavage [169]. Improvement in embryo developmental competence may be accomplished by LC supplementation through its potent antioxidant effect, its ability to reduce DNA damage, and by protecting the cells from the harmful effect of TNF- $\alpha$ [170] and hence exerts anti-inflammatory effects.

\section{Amelioration of oxidative injury by L-Carnitine and its congeners in Amyotrophic Lateral Sclerosis ALS / Motor Neuron Disease (MND)}

Oxidative damage is thought to be a major contributing factor in the death of motor neurons [171]. Oxidative injury can have both a primary role as well as a secondary role triggered by other mechanisms mentioned below. Reactive oxygen species (ROS) include superoxide, hydrogen peroxide $\left(\mathrm{H}_{2} \mathrm{O}_{2}\right)$, hydroxyl free radicals $\left(\mathrm{OH}^{\circ}\right)$ and nitric oxide $(\mathrm{NO})$. ROS readily react with lipids, proteins, and DNA to induce cellular damage [172]. The high metabolic activity of neurons leads to considerable ROS formation in these cells [173]. The high content of lipids and iron in nervous tissue may make the nervous system particularly sensitive to ROS damage [174]. Glutathione peroxidase (GPx), catalase (CAT), and superoxide dismutase (SOD) are all endogenous enzymatic antioxidants that counteract ROS damage. Toxicity resulting from mutated SOD has been directly implicated in the pathophysiology in familial ALS. Further support for the ROS hypothesis comes from elevated levels of protein carbonyls and 8-hydroxy-2-deoxyguanosine (8$\mathrm{OHdG}$ ), both markers of oxidative damage, in the motor cortex of sporadic ALS patients [175]. In addition, elevated plasma levels of 8-OHdG [176] and thiobarbituric acid reactive substances (TBARS) [177] have been identified in sporadic ALS patients compared to healthy controls. Possible benefit from exogenous neutraceuticals may result from their direct antioxidant activity and/or effects on endogenous enzyme pathways [178].

Mitochondrial dysfunction is now known to be a primary feature of ALS, with mitochondrial pathology observed at an early stage in the degeneration of the motor neurons [179]. Muscle mitochondria from ALS patients exhibit impaired electron transport, elevated free radical generation, and inability to buffer intracellular calcium $\left(\mathrm{Ca}^{2+}\right)$. Nuclear magnetic resonance (NMR), which can accurately measure mitochondrial metabolite levels in vivo, demonstrated a significant correlation between known mitochondrial pathology in ALS skeletal muscle and abnormal mitochondrial metabolite ratios in the cerebral cortex [180].

L-carnitine is an essential cofactor for the $\beta$-oxidation of long-chain fatty acids in mitochondria. It has also been shown to inhibit mitochondrial damage and apoptosis in vitro and in vivo. Early oral administration of L-carnitine significantly delayed symptom onset, prolonged motor function as assessed by rotorod, and extended survival in SOD-1 transgenic mice. In a second experiment 20 transgenic mice were injected with L-carnitine every two days after symptom onset. Survival of these mice was compared to that of 20 transgenic mice not receiving injections. Treatment with subcutaneous L-carnitine increased survival [181-182].

Amyotrophic lateral sclerosis (ALS), also known as motor neuron disease (MND), is an adult onset neurodegenerative disorder characterised by the degeneration of motor neurons of the motor cortex, brainstem, and spinal cord, resulting in progressive weakness and death. Several authors report increased oxidative damage in cortical neurons, spinal cords, and other tissues of each of sALS and fALS patients, and a compromised DNA-damage repair activity in ALS has been largely suggested [183-185]. 
In case of oxidative DNA damage, one of the major alterations in the DNA is the formation of 8-hydroxy2'-deoxyguanosine (8-OHdG), and increased levels of 8-OHdG have been identified in the neuronal DNA of the motor cortex of sALS patients, and in both sALS and fALS spinal cords [186]. The analysis of plasma, urine, and CSF of ALS patients revealed increased levels of 8-OHdG. Moreover, plasma and urine 8-OHdG levels increased significantly with time in the ALS group, and the rate of increase in urine 8OHdG levels with time was significantly correlated with disease severity [187]. Another study aimed at evaluating oxidative damage in blood and CSF of each of sALS and fALS patients showed that blood concentrations of hydroxyl radicals and cerebrospinal fluid (CSF) values of 8-OHdG and ascorbate free radical were higher in both sALS and fALS patients compared to controls [188].

Overall, mitochondrial dysfunction and oxidative DNA damage have been largely detected in motor neurons of either ALS patients or disease animal models [189]. A widespread PARP-1 activation was observed in several ALS brain regions [190], consistent with an increase in DNA damage. Overall, increased oxidative DNA damage, a widespread PARP-1 activation, and an increased expression of baseexcision repair (BER) enzymes were observed in neurons of $\mathrm{AD}, \mathrm{PD}, \mathrm{AD}, \mathrm{ALS}, \mathrm{MS}$ and $\mathrm{SD}$ individuals suggesting that DNA repair mechanisms could be activated following oxidative DNA attack in early stages of the neurodegenerative process [191]. L-carnitine and its congeners by acting as an iron-chelating membrane stabilizing antioxidant ergogenic aids, and modulating the expression of the DNA-damagerepairing enzyme PARP-1 and exerts a cumulative neuroprotective effects against ALS / MND.

\section{Neuroprotective effect of L-Carnitine and Acetyl-L-Carnitine on multiplesclerosis (MS)}

Multiplesclerosis (MS) is an inflammatory autoimmune disease of the central nervous system (CNS) that results in the demyelination of neurons. MS is perceived as a disease of autoimmunity against antigens of the central nervous system (CNS). The progressive neurodegenerative disease MS results in significant disability in affected patients. The pathological hallmarks of MS include infiltration of $\mathrm{T}$ cells and macrophages into the CNS, microglial activation, loss of myelin, and disruption of motor, sensory, and cognitive function [192-195]. Therefore, therapies are needed that specifically target the inflammatory response in the CNS without global immune impression. Therapies that manipulate upregulated metabolic pathways may prove effective anti-inflammatory therapies, because their blockage would specifically target cell populations responsible for promoting autoimmunity.

Multiple sclerosis (MS) is generally considered to be an inflammatory disease with a substantial autoimmune contribution [196]. Kalman et al proposed that mitochondrial abnormalities could drive the progressive inflammatory processes in MS [197]. Kalman et al proposed that mitochondrial abnormalities could drive the inflammatory processes in MS [198]. It has been demonstrated that, impaired ETCcomplex-I activity in chronic active plaque zones was associated with oxidative damage to mitochondrial DNA (mtDNA) [199]. Previous study reported that, mitochondrial complex-I gene variants are associated with MS [200].

After ALC was found to improve the extreme fatigue of chronic fatigue syndrome (CFS), it was tried for the fatigue of MS [201]. Carnitine plays a role in energy production by facilitating the transport of fatty acids into mitochondria. L-carnitine has been used successfully to treat fatigue in various clinical situations. Acetyl-L-carnitine (ALC) functions as a neurotransmitter and also appears to be a precursor to carnitine. In humans, peripheral blood mononuclear cells isolated from patients with infection show increased levels of acylcarnitines [202], indicating that immune-cell activation could increase the use of fatty acids (FAs) for metabolic fuel.

The acetyl ester of carnitine (ALCAR), a cellular component with an important role in energy metabolism control, has been proved to be effective in the treatment of fatigue in a large variety of diseases like MS. The effects of ALCAR on fatigue in MS could be mediated either by increased levels of stimulating neurotransmitters in SNC or through its cholinomimetic effect on striatum and prefrontal areas 
Texila International Journal of Basic Medical Science

Volume 2, Issue 1, Jul 2017

[203], areas that seem to play a role in MS-related fatigue. A randomised, double-blind, cross-over study showed a significant effect of ALCAR compared with amantadine in treating fatigue [204].

\section{Acetyl-L-Carnitine for multiple sclerosis (MS)}

Previous study reported that, supplementation of ALC significantly reduced the activity of nitric oxide synthase (NOS), nitrogen-centered free radicals (NO) and significantly increased the concentration of GSH in cerebrospinal fluid (CSF) of patients suffering from MS [205]. Several medications have been found to be beneficial for reducing the severity of fatigue. ALC is a cellular component with a vital role in energy metabolism. ALC has demonstrated effectiveness in fatigue reductions in many chronic fatigue syndrome (CFS) patients and in cancer patients undergoing chemotherapy. It has also demonstrated decrease in fatigue in MS patients [206] on LC and/or ALC supplementation. ALC is believed to have direct neurotransmitter action in the brain and may play a role in the excitatory and inhibitory pathways [207]. A LC significantly reduced fatigue in a placebo-controlled trial in MS patients [208]. When amantadine was compared with supplemental ALC in a crossover trial, ALC demonstrated superior efficacy and tolerance to amantadine [209]. Acylcarnitines have been postulated to cross the plasma membrane through an unknown mechanism and previous studies have shown that accumulation of these species during ischemia in the heart leads to disruption of membrane integrity and increases in intracellular calcium $\left(\mathrm{Ca}^{2+}\right)$ [210]. It has been documented that, L-carnitine sequestrates calcium $\left(\mathrm{Ca}^{2+}\right)$, inhibits xanthine oxidase (XO), increases total antioxidant status (TAS), reduces lipid peroxidation and oxidative DNA damage, repairs and stabilizes membranes and enhances oligodendrocyte marker expression and hence myelin sheath thickness after chronic hypoperfusion [210) and exerts neuroprotection.

Acetyl-L-carnitine (ALC) has been proposed to account for the antinociceptive efficacy of the drug in acute pain and in chronic pain after nerve injury in rats [211]. ALC-induced improvement of nerve regeneration together with prevention of neuronal sensory loss has also been observed in rats following peripheral nerve axotomy [212-214]. Recently, Hart and colleagues reported that six months of oral ALC treatment resulted in peripheral nerve regeneration of small sensory fibers as observed from skin biopsies in patients with distal symmetrical polyneuropathy [215].

L-Carnitine treatment to aged animals have decreased lipid peroxidation status by enhancing the antioxidant status in the aged animals. Carnitine is known to act as a chelator by decreasing cytosolic iron, which has a vital role in free radical production [216] and further carnitine inhibits xanthine oxidase and neutrophil superoxide radical production. Carnitine has also been reported to decrease lipid peroxidation and protect tissues from damage by repairing oxidized membrane lipids [217]. GSH nullifies peroxidative damage and is responsible for the regulation of intracellular level of lipid peroxidation during aging [218] and L-carnitine supplementation exerts sparing effects on methionine and GSH. Dobrzyńska I et al found that L-carnitine protected liver cell membranes against oxidative modifications in ethanol intoxicated rats through its ability to scavenge free radicals [219].

The protective effects of acetyl-L-carnitine might reflect its activity to improve energy metabolism, sequestering $\mathrm{Ca}^{2+}$, and repairing oxidized membrane/lipid bilayers, thereby suppressing the release of free electrons from mitochondrial electron transport chain (ETC) system, a prerequisite reaction to generate free radicals [220]. Furthermore, acetyl-L-carnitine may have a direct effect on the membrane, and may prevent cell damage by stabilizing and repairing the membranes against free radical damage. In various tumors and inflammatory diseases, elevated serum level of TNF- $\alpha$ decreased after treatment with LC [221]. L-Carnitine is able to stabilize mitochondrial membranes and increase the supply of energy to the organelle and protect the cell from apoptotic cell death [222], and hence proved to be potent anti-inflammatory antioxidant beneficial in various degenerative diseases. It has been documented that, L-carnitine and its congeners exerts membrane stabilizing effects by sequestering intracellular $\mathrm{Ca}^{2+}[223]$, and inhibits phospholipase A2 [224]. Also, LC has DNA-repair capability and decreased induction of aberrations in Ataxia telangiectasia (A-T) patients [225] and exerts antimutagenic effects. L-carnitine has been reported to inhibit free radical 
generation, thereby preventing the impairment of fatty acid $\beta$-oxidation in mitochondria and protecting tissues from damage by repairing oxidized membrane lipids [226].

\section{Conclusion}

L-Carnitine and its congeners are potent iron-chelating anti-inflammatory membrane -genome stabilizing poly (ADP-ribose) polymerase-1 inhibitory antioxidant ergogenic aids and its supplementation will be beneficial in the treatment of progressive neurodegenerative diseases such as Senile dementia (SD), Parkinson's disease (PD), Alzheimer's disease, Amyotrophic Lateral Sclerosis (ALS) and Multiple sclerosis (MS).

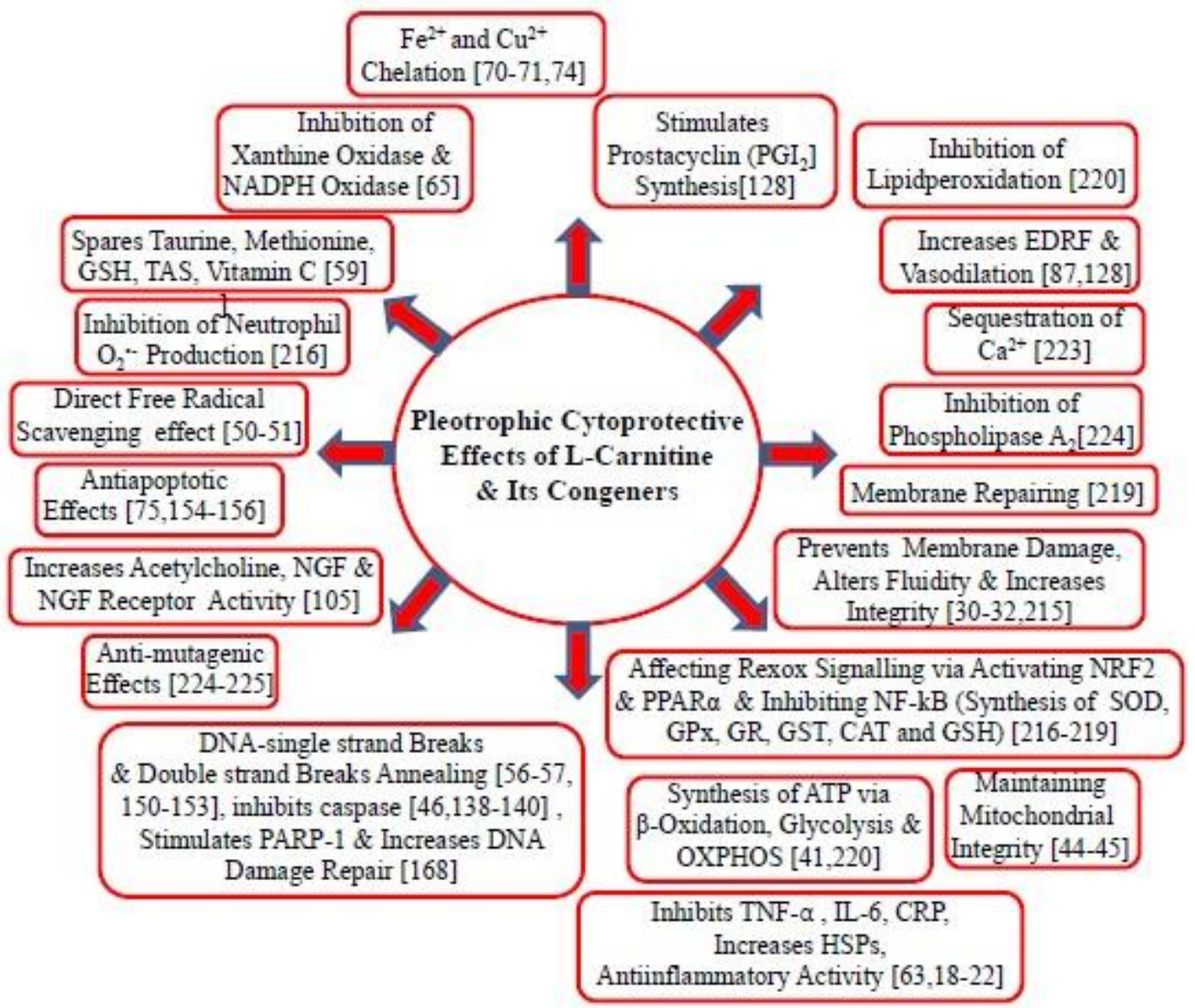

Pleotrophic Cytoprotective Epigenetic and DNA-Damage-Repair Molecular Mechanisms of L-Carnitine and Its Congeners in Aging And Age-Related Neurodegenerative Diseases 
Texila International Journal of Basic Medical Science

Volume 2, Issue 1, Jul 2017

\section{Neuroprotective Epigenetic and DNA Repairing Molecular Mechanisms of L-Carnitine and Its Congeners on Aging and Selected Age-Related Neurodegenerative Diseases}

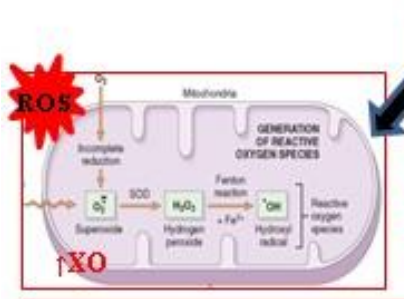

Induction of Membrane-DNA -Mitochondrial Damages, $\downarrow \downarrow$ ATP

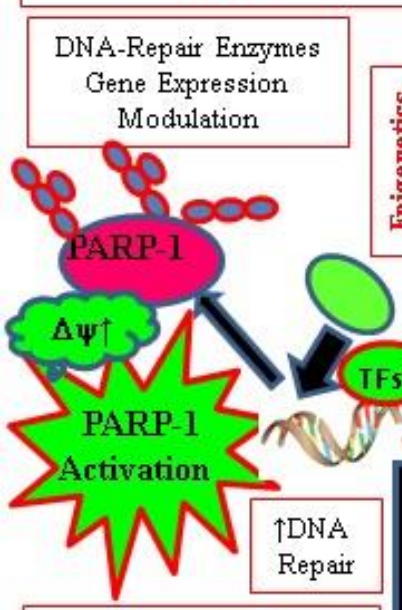

$\uparrow$ Doparninergic Neurone \& Peripheral Nerves Genome \& Membrane Stability

Cell Recovery

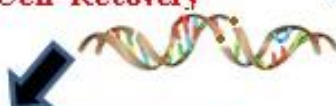

Neuroprotection

Aging,

Parkinsonism, Alzheimer's

Disease,

Amylotrop hic
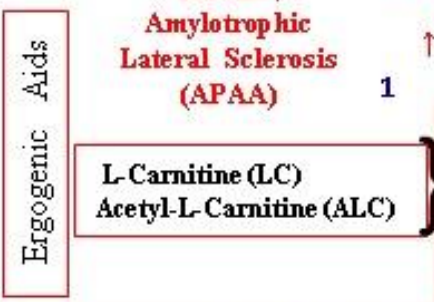

Aging, Parkinsonism, Alzheimer's Disease, Multiplesclerosis,

\section{Anylotrop hic Lateral Sclerosis (APMA)}

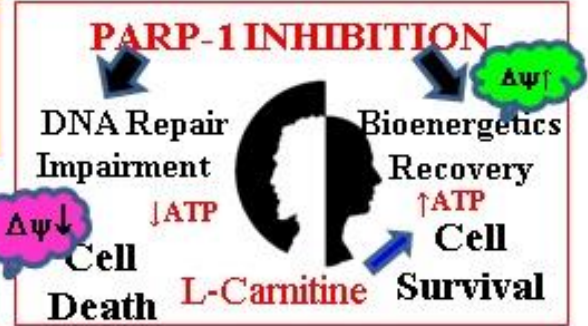

Death L-Carnitine Survival

PARP-1 as Janus Bifrons. Poly(ADP-ribosylation) jossessestwo seemingly opposing faces (Janus Bifrons): PARP-1 inhibition could lead on the one hand to DNA repair impairment and consequent cell death and on the other may spare $\mathrm{NAD}^{+}$

leading to mitochondria recovery and cell survive.

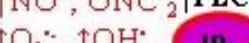
$\mathrm{O}_{2}, \uparrow \mathrm{OH}^{\circ}$,

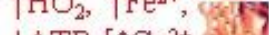
$\downarrow \mathrm{ATP},\left[\uparrow \mathrm{Ca}^{2+} \mathrm{e} \mathrm{d}, \mathrm{S}\right]$

† Pheripheral Nerves
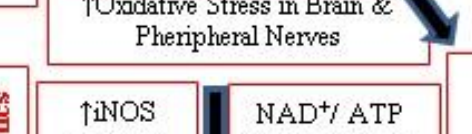

†eNOS

$\uparrow T N F-\alpha$

$\uparrow I L-1 \beta$

$\uparrow I L-2$

$\uparrow \mathrm{PGE}_{2}$

\section{$\mathrm{NAD}^{+} / \mathrm{ATP}$}

Consumption $\downarrow$ TAS

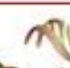

arion

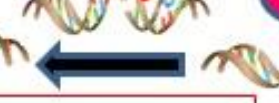

Low level DNA damage (Repairable)

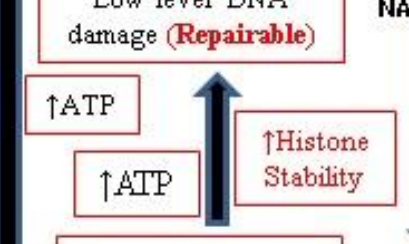

$\downarrow$ Biomarkers of OS in SNc, Striaturn, Hippocmpus, Peripheral Nerves
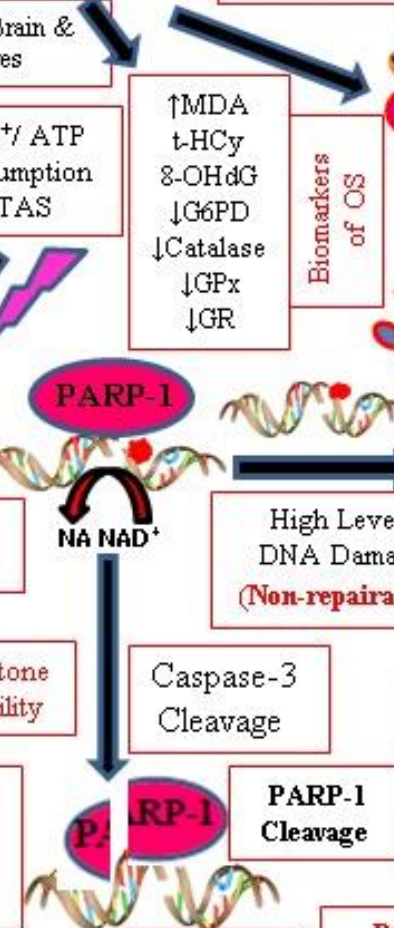

MDA $\mathrm{t}-\mathrm{HCy}$ 8-OHdG IG6PD $\downarrow$ Catalase $\downarrow \mathrm{GPx}$ $\downarrow \mathrm{GR}$

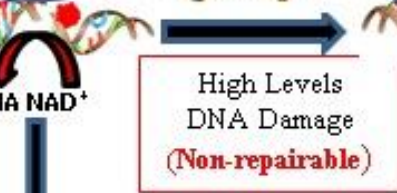

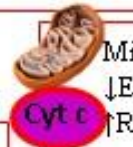

Mitochondrial Dysfunction, $\downarrow$ ETC, $\downarrow$ ATP, Cyt-c Release ROS \& $\uparrow$ Nitrosative Stress Accumulation of $\mathrm{Ca}^{2+}$ Caspase-3 \& 9 Activation Activation of Endonucleases DNA-SSBs, DNA-DSBs, Q gNN Fragmenfation
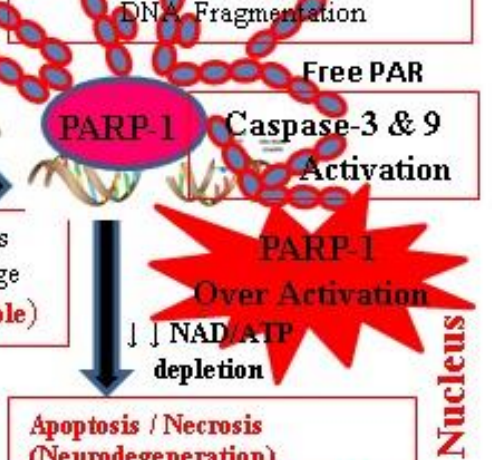
Apoptosis / Necrosis
(Neurodegeneration)

Loss of Dopaminergic Neurones Depletion of Neurotranuritters

Neurodegeneration

\section{$\downarrow$ PICKs}

$\downarrow$ IOS, $\downarrow N S, \downarrow \mathrm{XO}, \downarrow L \mathrm{LP}$,

$\downarrow$ t- $\mathrm{HCy}$, Iron-Chelation,

Sequestration of $\mathrm{Ca}^{2+}$

Sparing,
$\uparrow$ Antioxidant

$\uparrow$ Antioxidant

Status

Iron-Chelating

Antiinflammatory

Antioxidant \&

PARP-1

Inhibitory Effects

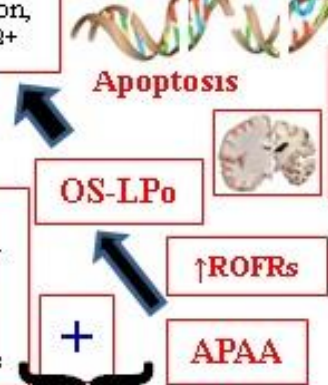

Brain Aging, Parkinson's Disease (PD), Alzheimer's Disease (AD), Multiplesclerosis (MS), Amylotrophic Lateral Sclerosis

LC- L-Camitine, Acetyl-L-Camitine PARP-1- Poly(ADP-ribose) polymerase-1 MFB-Median forebrainbundle iNOS-Intucible nitric oxide synthase eNOS-Endothelial nitric oxide synthase ROFRs- Reactive oxygen free radicals OS-Oxidative stress; $\mathrm{t}$-HCy-Total hmocysteme XO-Xanthineoxidase ; SNc-Substantianigra NS-Hitrosative stress; LPo-Lipidperoxidation; MDA-Malondialdehyde;

TAS-Total antioxidant status

DNA-SSBs-DNA single strand breaks DNA-DSBs-DHA double strand breals PICKs-Proinflammatory cytolines

Neuroprotective Epigenetic and DNA-Damage-Repairing Molecular Mechanisms of L-Carnitine and Its Congeners Acetyl-L-Carnitine, Propionylcarnitine Against Aging and Age-Related Neurodegenerative Diseases

\section{References}


[1]. Abd-Allah AR, Al-Majed AA, Al-Yahya AA, Fouda SI, Al-Shabana OA. L-Carnitine halts apoptosis and myelosuppression induced by carboplatin in rat bone marrow cell cultures (BMC). Arch Toxicol 2005; 79: 406-413.

[2]. Arsuini, A. 1992. Carnitine and its acyl esters as secondary antioxidants? Am. Heart J. 123: 1726-1727.

[3]. Abdul Muneer PM, Alikunju S, Szlachetka AM, Haorah J. Inhibitory effects of alcohol on glucose transport across the blood-brain barrier leads to neurodegeneration: preventive role of acetyl-L-carnitine. Psychopharmacology (Berl). 2011 Apr; 214(3):707-718.

[4]. Ando, S., T. Tadenuma, Y. Tanaka et al. 2001. Enhancement of learning capacity and cholinergic synaptic function by carnitine in aging rats. J. Neurosci. Res. 66: 266-271.

[5]. Arduini, A., S. Dottori, F. Molajoni et al. 1995. Is the carnitine system part of the heart antioxidant network? In The Carnitine System: A New Therapeutical Approach to Cardiovascular Medicine, pp. 169-181. Kluwer. Dordrecht.

[6]. Aitken RJ, Clarkson JS. Cellular basis of defective sperm function and its association with the genesis of reactive oxygen species by human spermatozoa. J Reprod Fertil 1987; 81: 459-469.

[7]. Aliabadi E, Soleimani Mehranjani M, Borzoei Z, Talaei-Khozani T, Mirkhani H, Tabesh H. Effects of Lcarnitine and L-acetyl-carnitine on testicular sperm motility and chromatin quality. Iran J Reprod Med. 2012 Mar; 10(2):77-82.

[8]. Angelucci L, Ramacci MT, Taglialatela G, Hulsebosch C, Morgan B, et al. (1988). Nerve growth factor binding in aged rat central nervous system: effect of acetyl-L-carnitine. J Neurosci Res 20: 491-496.

[9]. Arduini A, Rossi M, Mancineili G, Beigiglio M, Scurti R, Radatti GL, Shohet SB. Effect of L-carnitine and acetyl-L-carnitine on the human erythrocyte membrane stability and deformability. Life Sci 1990; 47:2395-2400.

[10]. Abuzahra, Mona Abd El-Latif; Mustafa, Sherifa Abd-Elsalam. Nitric Oxide and Oxidative Stress Properties of L-Carnitine in Diabetic Hypertensive Rats Biochemical \& Histological Study. Middle East Journal of Internal Medicine. Jun2014, Vol. 7 Issue 2, p19-31. 13p.

[11]. Andrieu-Abadie N, Jaffrezou JP, Hatem S, Laurent G, Levade T, and Mercadier JJ. L-Carnitine prevents doxorubicin- induced apoptosis of cardiac myocytes: role of inhibition of ceramide generation. FASEB J 13: 15011510, 1999.

[12]. Angelucci L, TRamacci M, Taglialatela G, Hulsebosch C, Morgan B, Werrbach-Perez K, Perez-Polo R. Nerve growth factor binding in aged rat central nervous system: effect of acetyl-L-carnitine. J Neurosci Res. 1988 Aug; 20(4):491-496.

[13]. Beal, MF; Lang, AE; AC, L. Neurodegenerative diseases: neurobiology, pathogenesis, and therapeutics. Cambridge, UK New York: Cambridge University Press; 2005.

[14]. Berni, A., Meschini, R., Filippi, S., Palitti, F., Arnicisb, A., Chessab, L., 2008. L--carnitme enhances resistance to oxidative stress by reducing DNA damage in Ataxia telangiectasia cells. Mut. Res. 650, 165-174.

[15]. Bogdanov M, Brown RH, Matson W, et al. Increased oxidative damage to DNA in ALS patients. Free Radical Biology \& Medicine 2000; 29(7):652-658.

[16]. Baxter, A. G. The origin and application of experimental autoimmune encephalomyelitis. Nat Rev Immunol 7, 904-912, 2007.

[17]. Bonnefont-Rousselot D, Lacomblez L, Jaudon M, et al. Blood oxidative stress in amyotrophic lateral sclerosis. Journal of the Neurological Sciences 2000; 178(1):57-62.

[18]. Boerrigter Miet, Franceschi C, Arrigoni-Martelli E, J.Y. Wei JY, J. Vijg J. The effect of L-carnitine and acetylL-carnitine on the disappearance of DNA single-strand breaks in human peripheral blood lymphocytes. Carcinogenesis. 1993; Oct, 14(10), 2131-36.

[19]. Boerrigter ME, Franceschi C, Arrigoni-Martelli E, Wei JY, Vijg J. The effect of L-carnitine and acetyl-Lcarnitine on the disappearance of DNA single-strand breaks in human peripheral blood lymphocytes. Carcinogenesis. 1993 Oct; 14(10):2131-6

[20]. Boerrigter, M.E., C. Franceschi, E. Arrigoni-Martelli et al. 1993. The effect of Lcarnitine and acetyl-L-carnitine on the disappearance of DNA single-strand breaks in human peripheral blood lymphocytes. Carcinogenesis 14: 21312136. 
Texila International Journal of Basic Medical Science

Volume 2, Issue 1, Jul 2017

[21]. Bacon, B.R., R. Neill and C.H. Park, 1986. Iron-induced peroxidative injury to isolated rat hepatic mitochondria. J. Free Radicals Biol. Med. 2: 339-342.

[22]. Baghaei A, Solgi R, Jafari A, Abdolghaffari AH, Golaghaei A, Asghari MH, Baeeri M, Ostad SN, Sharifzadeh M, Abdollahi M.Molecular and biochemical evidence on the protection of cardiomyocytes from phosphine-induced oxidative stress, mitochondrial dysfunction and apoptosis by acetyl-L-carnitine. Environ Toxicol Pharmacol. 2016 Mar; 42:30-37.

[23]. Buyse J, Swennen Q, Niewold TA, Klasing KC, Janssens GPJ, Baumgartner M, et al. Dietary 1-carnitine supplementation enhances the lipopolysaccharide-induced acute phase protein response in broiler chickens. Veterinary Immunol Immunopathol 2007; 118: 154159.

[24]. Beal, MF, Lang, AE, AC, L. Neurodegenerative diseases: neurobiology, pathogenesis, and therapeutics. Cambridge, UK New York: Cambridge University Press; 2005.

[25]. Bieber LL, Krahling JB, Clarke PR, Valkner KJ, Tolbert NE. Carnitine acyltransfe rases in rat liver peroxisomes. Arch Biochem Biophys 1981; 211: 599-604.

[26]. Bieber LL. Carnitine. Annu Rev Biochem 1988; 57:261-83.

[27]. Brevetti G, Attisano T, Perna S, et al. Effect of L-carnitine on the reactive hyperemia in patients affected by peripheral vascular disease: a double-blind, crossover study. Angiology. 1989; 40:857-862.

[28]. Bresolin, N., L. Freddo, L. Vergani and C. Angelini. 1982. Carnitine, carnitine acyltransferases, and rat brain function. Exp. Neurol. 78: 285-292.

[29]. Costell, M., J.E. O'Cconnor and S. Grisolia. 1989. Age-dependent decrease of carnitine content in muscle of mice and humans. Biochem. Biophys. Res. Commun. 161: 1135-1143.

[30]. Carta, A., Calvani, M., Bravi, D. and Bhuachalla, S. N. (1993). In Alzheimer's disease: Amyloid Precursor Proteins, Signal Transduction and Neuronal Transplantation, eds. Wurtman, R. J., Corkin, S., Growdon, J. H. \& Nitsch, R. M. (New York Academy of Sciences, New York), Vol. 695, pp. 324-326.

[31]. Chang B, Nishikawa M, Sato E, Utsumi K, Inoue M. L-carnitine inhibits cisplatin-induced injury of the kidney and small intestine. Arch Biochem Biophys 2002; 405:55-64.

[32]. Cress, A. P., Fraker, P. J and Bieber, L. L. Carnitine and acylcarnitine levels of human peripheral blood lymphocytes and mononuclear phagocytes. Biochim Biophys Acta 992, 135-139 (1989).

[33]. Cakir O, Erdem K, Oruc A, Kilinc N, Eren N (2003) Neuroprotective effect of N-acetylcysteine and hypothermia on the spinal cord ischemia-reperfusion injury. Cardiovasc Surg 11: 375-379.

[34]. Calabrese V, Scapagnini G, Ravagna A, et al. Disruption of thiol homeostasis and nitrosative stress in the cerebrospinal fluid of patients with active multiple sclerosis: evidence for a protective role of acetylcarnitine. Neurochem Res 2003; 28:1321-1328.

[35]. Craig J. McMackin, Michael E. Widlansky, Naomi M. Hamburg, Alex L. Huang, Susan Weller, Monika Holbrook, Noyan Gokce, Tory M. Hagen, John F. Keaney, Jr., and Joseph A. Vita. Effect of Combined Treatment with Alpha Lipoic Acid and Acetyl-L-Carnitine on Vascular Function and Blood Pressure in Coronary Artery Disease Patients. J Clin Hypertens (Greenwich). 2007 Apr; 9(4): 249-255.

[36]. Chatzinikolaou, G., Karakasilioti, I., and Garinis, G.A. (2014). DNA damage and innate immunity: links and trade-offs. Trends Immunol. 35, 1-7.

[37]. Chiechio S, Caricasole A, Barletta E, Storto M, Catania MV, Copani A, Vertechy M, Nicolai R, Calvani M, Melchiorri D, Nicoletti F. L-Acetylcarnitine induces analgesia by selectively up-regulating mGlu2 metabotropic glutamate receptors. Mol. Pharmacol. 2002; 61:989-96.

[38]. Costell M, O'Connor JE, Grisolía S. Age-dependent decrease of carnitine content in muscle of mice and humans. Biochem Biophys Res Commun. 1989 Jun 30; 161 (3):1135-43.

[39]. Dobrzyńska I, Szachowicz-Petelska B, Skrzydlewska E, Figaszewski Z. Effect of L-carnitine on liver cell membranes in ethanol-intoxicated rats. Chem Biol Interact 2010; 188: 44-51.

[40]. De Rosa M, Boggia B, Amalfi B, Zarrilli S, Vita A, Colao A, et al. Correlation between seminal carnitine and functional spermatozoal characteristics in men with semen dysfunction of various origins. Drugs R D 2005; 6: 1-9.

[41]. Dayanandan, P.Kumar, T. Kalaiselvi and C. Panneerselvam. Effect of L-Carnitine on blood lipid composition in Atherosclerotic rats. J. Clin. Biochem, Nutr. 17, 81- 87, 1994. 
[42]. Deeks SG. Antiretroviral agents: the next generation. AIDS Clin. Care. 1998; May, 10 (5):33-6, 39-40. Review. [43]. Dolezal, V. and S. Tucek. 1981. Utilization of citrate, acetylcarnitine, acetate, pyruvate, and glucose for the synthesis of acetylcholine in rat brain slices. J. Neurochem. 36: 1323-1330.

[44]. Dayanandan, P.Kumar and C. Panneerselvam.Protective role of L-carnitine on liver and heart lipid peroxidation in atheroscerotic rats. J. Nutr. Biochem, 2001 May; 12(5): 254-257.

[45]. Ew132. D’Amours, D., Desnoyers, S., D’Silva, I., and Poirier, G.G. (1999). Poly (ADPribosyl) action reactions in the regulation of nuclear functions. Biochem. J. 342, 249-268.

[46]. Ewan EE, Hagg T. Intrathecal Acetyl-L-Carnitine Protects Tissue and Improves Function after a Mild Contusive Spinal Cord Injury in Rats. J Neurotrauma. 2016 Feb 1; 33(3):269-77.

[47]. Esposito E, Rotilio D, Di Matteo V, Di Giulio C, Cacchio M, Algeri S. A review of specific dietary antioxidants and the effects on biochemical mechanisms related to neurodegenerative processes. Neurobiology of Aging 2002; 23 (5):719-735.

[48]. ERijk, M.C., Launer, L.J., Berger, K., Breteler, M.M., Dartigues, J.F., Baldereschi, M., Fratiglioni, L., Lobo, A., Martinez-Lage, J., Trenkwalder, C and Hofman, A. (2000). Prevalence of Parkinson's disease in Europe: a collaborative study of populationbased cohorts. Neurology, Vol.54, No.11, pp. S21-S23

[49]. Ford, D. A., Han, X., Horner, C. C and Gross, R. W. Accumulation of unsaturated acylcarnitine molecular species during acute myocardial ischemia: metabolic compartmentalization of products of fatty acyl chain elongation in the acylcarnitine pool. Biochemistry 35, 7903-7909, 1996.

[50]. Folts, J.D., Shug, A.L., Koke, J.R. and Bittar, N. (1978) Am. J.Cardiol. 41, 1209-1214.

[51]. Foster DW. The role of the carnitine system in human metabolism. Ann N Y Acad Sci 2004; 1033: 1-16.

[52]. Ferreira GC, McKenna MC.L-Carnitine and Acetyl-L-carnitine Roles and Neuroprotection in Developing Brain. Neurochem Res. 2017 May 16.

[53]. Ferrante RJ, Browne SE, Shinobu LA, et al. Evidence of increased oxidative damage in both sporadic and familial amyotrophic lateral sclerosis. Journal of Neurochemistry 1997; 69 (5):2064-2074.

[54]. Fernandes S, Salta S, Summavielle T. Methamphetamine promotes $\alpha$-tubulin deacetylation in endothelial cells: the protective role of acetyl-1-carnitine. Toxicol Lett. 2015 Apr 16; 234 (2):131-8.

[55]. Furuno T, Kanno T, Arita K, Asami M, Utsumi T, Doi Y, Inoue M, Utsumi K. Roles of long chain fatty acids and carnitine in mitochondrial membrane permeability transition. Biochem Pharmacol 2001; 62: 1037-1046.

[56]. Furuno T, Kanno T, Arita K, Asami M, Utsumi T, Doi Y, Inoue M, Utsumi K. Roles of long chain fatty acids and carnitine in mitochondrial membrane permeability transition. Biochem Pharmacol. 2001 Oct 15; 62(8):1037-46.

[57]. Ford DA. Alterations in myocardial lipid metabolism during myocardial ischemia and reperfusion. Prog Lipid Res2002; 41: 6-26.

[58]. Griendling KK, Fitzgerald GA. Oxidative stress and cardiovascular injury: part II: animal and human studies. Circulation. 2003;108: 2034-2040.

[59]. Gottlieb, R.A., Burleson, K.O., Kloner, R.A., Babior, B.M. and Engler, R.L. (1994) J. Clin. Invest. 94, 16211628.

[60]. Gasser P, Martina B, Dubler B. Reaction of capillary blood cell velocity in nailfold capillaries to L-carnitine in patients with vasospastic disease. Drugs Exp Clin Res. 1997; 23: 39-43.

[61]. Gurney ME, Cutting FB, Zhai P, et al. Benefit of vitamin E, riluzole, and gabapentin in a transgenic model of familial amyotrophic lateral sclerosis [see comments]. Annals of Neurology 1996; 39(2): 147-157.

[62]. Grazi G, Meriggioli M, Donati G. Can the treatment with L-carnitine improve the inflammation in chronic hemodialysis patients? G Ital Nefrol 2004; 21: 204-207.

[63]. Gulcin I. Antioxidant and antiradical activities of L-carnitine. Life Sci 2006; 78: 803-811.

[64]. G. E. Kisby, J. Milne, and C. Sweatt, "Evidence of reduced DNA repair in amyotrophic lateral sclerosis brain tissue," NeuroReport, vol. 8, no. 6, pp. 1337-1340, 1997.

[65]. G. E. Kisby, J. Milne, and C. Sweatt. "Evidence of reduced DNA repair in amyotrophic lateral sclerosis brain tissue," NeuroReport, vol. 8, no. 6, pp. 1337-1340, 1997.

[66]. Gadaleta MN, Petruzzella V, Fracasso F, Fernandez-Silva P, Cantatore P. Acety-L-carnitine increases cytochrome oxidase subunit I mRNA content in hypothyroid rat Liver. FEBS, Lett, 1990, 277, 191-193. 
Texila International Journal of Basic Medical Science

Volume 2, Issue 1, Jul 2017

[67]. Gelbard, H.A., James, H.J., Sharer, L.R., Perry, S.W., Saito, Y., Kazee, A.M., Blumberg, B.M. and Epstein, L.G. (1995) Neuropathol. Appl. Neurobiol. 21, 208-217.

[68]. Gadaleta MN, Petruzzella M, Renis M, Fracasso F, Antatore P. Reduced mitochondrial DNA transcription in two brain regions of senescent rats: Effect of acetyl-L-carnitine. In: S. Quazliariello, F. Papa, Palmieri and C. Seccombe Edn. Structure, function and biogenesis of energy transfer system. Elsevier, Amsterdam, pp. 135-138.

[69]. Gulcin I (2006). Antioxidant and antiradical activities of L-carnitine. Life Sci 78:803-811.

[70]. Gabryel B, Adamek M, Pudelko A, Malecki A, Trzeciak HI. Piracetam and vinpocetine exert cytoprotective activity and prevent apoptosis of astrocytes in vitro in hypoxia and reoxygenation. Neurotoxicology 2002; 23(1):1931.

[71]. Greenland P, Alpert JS, Beller GA, Benjamin EJ, Budoff MJ, Fayad ZA, et al. 2010. ACCF/AHA guideline for assessment of cardiovascular risk in asymptomatic adults: a report of the American College of Cardiology Foundation/American Heart Association Task Force on Practice Guidelines. J Am Coll Cardiol 2010; 56:e50-e103.

[72]. Geremia, E., C. Santoro, D. Baratta et al. 1988. Antioxidant action of acetyl-Lcarnitine: in vitro study. Med. Sci. Res. 16: 699-700.

[73]. Gadaleta, M.N., V. Petruzzella, M. Renis et al. 1990. Reduced transcription of mitochondrial DNA in the senescent rat: tissue dependence and effect of L-carnitine. Eur. J. Biochem. 187: 501-506.

[74]. Hagen, T.M., R.T. Ingersoll, C.M. Wehr et al. 1998. Acetyl-L-carnitine fed to old rats partially restores mitochondrial function and ambulatory activity. Proc. Natl. Acad. Sci. USA 95: 9562-9566.

[75]. Hagen, T.M., J. Liu, J. Lykkesfeldt et al. 2002. Feeding acetyl-L-carnitine and lipoic acid to old rats significantly improves metabolic function while decreasing oxidative stress. Proc. Natl. Acad. Sci. USA 99: 18701875.

[76]. Hagen TM, Moreau R, Suh JH, Visioli F. Mitochondrial decay in the aging rat heart: evidence for improvement by dietary supplementation with acetyl-L-carnitine and/or lipoic acid. Ann. N Y Acad. Sci. 2002; 959, 491-507.

[77]. Haorah J, Floreani NA, Knipe B, Persidsky Y. Stabilization of superoxide dismutase by acetyl-1-carnitine in human brain endothelium during alcohol exposure: novel protective approach. Free Radic Biol Med. 2011 Oct 15; 51(8):1601-9.

[78]. Haleagrahara $\mathrm{N}$ and Ponnusamy Kumar. Neuroprotective effect of Centella asiatica extract (CAE) on experimentally induced parkinsonism in aged Sprague-Dawley rats. J Toxicol Sci. 2010; 35 (1):41-47.

[79]. Hagen TM, Liu J, Lykkesfeldt J, et al. Feeding acetyl-L-carnitine and lipoic acid to old rats significantly improves metabolic function while decreasing oxidative stress. Proc Natl Acad Sci U S A. 2002; 99: 1870-1875.

[80]. Hagen TM, Ingersoll RT, Lykkesfeldt J, et al. (R)-alpha lipoic acid-supplemented old rats have improved mitochondrial function, decreased oxidative damage, and increased metabolic rate. FASEB J. 1999; 13: 411-418.

[81]. Hagen TM, Ingersoll RT, Wehr CM, et al. Acetyl-L-carnitine fed to old rats partially restores mitochondrial function and ambulatory activity. Proc Natl Acad Sci U S A. 1998; 95: 9562-9566.

[82]. Hagen TM, Moreau R, Suh JH, et al. Mitochondrial decay in the aging rat heart: evidence for improvement by dietary supplementation with acetyl-L-carnitine and/or lipoic acid. Ann N Y Acad Sci. 2002; 959: 491-507.

[83]. Hind Abdullah Seed Alzahrani. Protective effect of L-carnitine against acrylamide-induced DNA damage in somatic and germ cells of mice. Saudi J Biol Sci. 2011 Jan; 18(1): 29-36

[84]. Ha, H.C., and Snyder, S.H. (1999). Poly (ADP-ribose) polymerase is a mediator of necrotic cell death by ATP depletion. Proc. Natl. Acad. Sci. USA 96, 13978-13982.

[85]. Hagen, T.M., R.T. Ingersoll, J. Lykkesfeldt et al. 1999. (R)-Alpha-lipoic acid-supplemented old rats have improved mitochondrial function, decreased oxidative damage, and increased metabolic rate. FASEB J. 13: 411-418. [86]. Hussein Abdelrazik, M.D, Rakesh Sharma, Reda Mahfouz, and Ashok Agarwal. L-Carnitine decreases DNA damage and improves the in vitro blastocyst development rate in mouse embryos. Fertility and Sterility, 2009 Feb; 91(2):589-96.

[87]. Halliwell B. Role of free radicals in the neurodegenerative diseases: therapeutic implications for antioxidant treatment. Drugs \& Aging 2001; 18 (9):685-716.

[88]. Hart AM, Wiberg M, Terenghi G. Pharmacological enhancement of peripheral nerve regeneration in the rat by systemic acetyl-L-carnitine treatment. Neurosci. Lett. 2002; 334: 181-185. 
[89]. Hiromi Yano, Eri Oyanagi, Yasuko Kato, Yoshiyuki Samejima, Junzo Sasaki and Kozo Utsumi. L-Carnitine is essential to $\beta$-oxidation of quarried fatty acid from mitochondrial membrane by PLA2. Molecular and Cellular Biochemistry, Sep 2010, 342, 1, 95-100.

[90]. Hart AM, Wiberg M, Youle M, Terenghi G. Systemic acetyl-L-carnitine eliminates sensory neuronal loss after peripheral axotomy: a new clinical approach in the management of peripheral nerve trauma. Exp. Brain Res. 2002; 145: 182-189.

[91]. Hart AM, Wilson AD, Montovani C, Smith C, Johnson M, Terenghi G, Youle M. Acetyl-1-carnitine: a pathogenesis based treatment for HIV-associated antiretroviral toxic neuropathy. AIDS. 2004; 18:1549-1560.

[92]. Hagen, T.M., V. Vinarsky, C.M. Wehr and B.N. Ames. 2000. (R)-Alpha-lipoic acid reverses the age-associated increase in susceptibility of hepatocytes to tert-butylhydroperoxide both in vitro and in vivo. Antioxid. Redox Signal. 2: $473-483$.

[93]. Hagen TM, Ingersoll RT, Lykkesfeldt J, et al. (R)-alphalipoic acid-supplemented old rats have improved mitochondrial function, decreased oxidative damage, and increased metabolic rate. FASEB J. 1999; 13: 411-418.

[94]. Horiuchi M, Kobayashi K, Tomomura M, Kuwajima M, Imamura Y, Koizumi T, Nikaido H, Hayakawa J, Saheki T. Carnitine administration to juvenile visceral steatosis mice corrects the suppressed expression of urea cycle enzymes by normalizing their transcription. J Biol Chem. 1992; Mar 15, 267(8), 5032-5035.

[95]. H. Kikuchi, A. Furuta, K. I. Nishioka, S. O. Suzuki, Y. Nakabeppu, and T. Iwaki. "Impairment of mitochondrial DNA repair enzymes against accumulation of 8-oxo-guanine in the spinal motor neurons of amyotrophic lateral sclerosis". Acta Neuropathologica, vol. 103, no. 4, 408-414, 2002.

[96]. Ishii T1, Shimpo Y, Matsuoka Y, Kinoshita K.Anti-apoptotic effect of acetyl-l-carnitine and I-carnitine in primary cultured neurons. Jpn J Pharmacol. 2000 Jun; 83 (2):119-24.

[97]. Javier Blesa, Ines Trigo-Damas, Anna Quiroga-Varela and Vernice R.Jackson-Lewis. Oxidative stress and Parkinson's disease. Front Neuroanat. 2015 Jul 8; 9: 91-99.

[98]. Jeffrey Rosenfeld and Amy Ellis. Nutrition and Dietary Supplements in Motor Neuron Disease. Phys Med Rehabil Clin N Am. 2008 Aug; 19(3): 573-589.

[99]. Kidd, P.M. 1999. A review of nutrients and botanicals in the integrative management of cognitive dysfunction. Altern. Med. Rev. 4: 144-161.

[100]. Kalaiselvi, T. and C. Panneerselvam. 1998. Effect of L-carnitine on the status of lipidperoxidation and antioxidants in aging rats. J. Nutr. Biochem. 9: 575-581.

[101]. Kaufmann, S.H., Desnoyers, S., Ottaviano, Y., Davidson, N.E., and Poirier, G.G. (1993). Specific proteolytic cleavage of poly (ADP-ribose) polymerase: an early marker of chemotherapy-induced apoptosis. Cancer Res. 53, 3976-3985.

[102]. Koudelova J, Mourek J, Drahota Z, Rauchova H (1994). Protective effect of carnitine on lipoperoxide formation in rat brain. Physiol Res 43:387-389.

[103]. Kalaiselvi, T and C. Panneerselvam.1998. Effect of L-carnitine on the status of lipidperoxidation and antioxidants in aging rats. J. Nutr. Biochem. 9: 575-581.

[104]. Kanter M, Topcu-Tarladacalisir Y, Parlar S. Antiapoptotic effect of L-carnitine on testicular irradiation in rats. J Mol Histol 2010; 41: 121-128.

[105]. Kidd PM. Multiple sclerosis, autoimmune inflammatory disease: prospects for its integrative management. Altern Med Rev 2001; 6: 540-566.

[106]. Kalman B, Leist TP. A mitochondrial component of neurodegeneration in multiple sclerosis. Neuromolecular Med 2003; 3:147-158.

[107]. Kuratsune H, Yamaguti K, Lindh G et al (2002). Brain regions involved in fatigue sensation: reduced acetylcarnitine uptake into the brain. Neuroimage 17:1256-1265.

[108]. Kumar Ponnusamy, Sindhu Babulogaiah, Neethu Gopal and Srisharan Manavalan.Acetyl-L-Carnitine and Quercetin as PARP-1 Modulators: Implication on Alzheimer's Disease. Poster Presntation, The Lancet Neurology Conference Preclinical neurodegenerative disease: towards prevention and early diagnosis Oct 19-21, 2016, Park Plaza Riverbank, London, UK. Kumar Ponnusamy, Sindhu Babulogaiah, Neethu Gopal and Srisharan Manavalan. Impact of Poly (ADP-ribose) Polymerase (PARP- Modulators on the Biomarkers of Alzheimer's Disease in Aged 
Texila International Journal of Basic Medical Science

Volume 2, Issue 1, Jul 2017

Mice. The Lancet Neurology Conference Preclinical neurodegenerative disease: towards prevention and early diagnosis Oct 19-21, 2016, Park Plaza Riverbank, London, UK.

[109]. K. Ponnusamy and J.R. Naidu. "Neuroprotective effect of L-carnitine and Centella asiatica extract on 6hydroxydopamine (6-OHDA)-induced changes in the repair-mechanism and genotoxicity in aged rats", Parkinsonism and Related Disorders, Vol.18, No.2 (Supplement), 11.12.2011.

[110]. Kumar, P and Jegathambigai, R.N. "Levo-Carnitors as emerging neuroprotective molecular medicines", Parkinsonism and Related Disorders, Vol.18, No.2 (Supplement), P1, 11.12.2011.

[111]. Kira Y, Nishikawa M, Ochi A, Sato E, Inoue M. L-carnitine suppresses the onset of neuromuscular degeneration and increases the life span of mice with familial amyotrophic lateral sclerosis. Brain Research 2006;1070(1):206-214.

[112]. Kidd PM. A review of nutrients and botanicals in the integrative management of cognitive dysfunction. Altern Med Rev 1999; 4: 144-161.

[113]. Korn, $\mathrm{T}$ et al. Myelin-specific regulatory $\mathrm{T}$ cells accumulate in the CNS but fail to control autoimmune inflammation. Nat Med 13, 423-431 (2007).

[114]. Kornek, B. et al. Multiple sclerosis and chronic autoimmune encephalomyelitis: a comparative quantitative study of axonal injury in active, inactive, and remyelinated lesions. Am J Pathol 157, 267-276, 2000.

[115]. Kocogullari CU, Becit N, Erkut B, Keles MS, Ceviz M, et al. (2008) Prevention of reperfusion injury of the spinal cord in aortic surgery: an experimental study. Surg Today 38: 237-244.

[116]. Liu J, Killilea DW, Ames B. Age-associated mitochondrial oxidative decay: improvement of carnitine acetyltransferase substrate-binding affinity and activity in brain by feeding old rats' acetyl-L-carnitine and/or R-lipoic acid. PNAS 2002; 99(4): 1876-1881.

[117]. Liu, J., E. Head, A. Gharib et al. 2002. Memory loss in old rats is associated with brain mitochondrial decay and RNA/DNA oxidation: partial reversal by feeding acetyl-L-carnitine and/or R- $\alpha$-lipoic acid. Proc. Natl. Acad. Sci. USA 99: 2356-2361.

[118]. Lee, V. M. and Trojanowsky, J.Q. (2006). Mechanisms of Parkinson's disease linked to pathological alphasynuclein: new targets for drug discovery. Neuron, Vol.52, No.1, (October 2006), pp. 33-38.

[119]. Langelier, M.-F., Planck, J.L., Roy, S., and Pascal, J.M. (2012). Structural basis for DNA damage-dependent poly (ADP-ribosyl) action by human PARP-1. Science 336, 728-732.

[120]. Liu J, Head E, Kuratsune H, Cotman CW, Ames BN. Comparison of the effects of 1-carnitine and acetyl-1carnitine on carnitine levels, ambulatory activity and oxidative stress biomarkers in the brain of old rats. Ann N Y Acad Sci 2004; 1033: 117-31.

[121]. Liu, J., H. Atamna, H. Kuratsune and B.N. Ames. 2002. Delaying brain mitochondrial decay and aging with mitochondrial antioxidants and metabolites. Ann. N.Y. Acad. Sci. 959: 133-166.

[122]. Lane, T. E. et al. A central role for CD4 (1) T cells and Rantes in virus-induced central nervous system inflammation and demyelination. J Virol 74, 1415-1424, 2000.

[123]. Lu F, Selak M, O'Connor J, et al. Oxidative damage to mitochondrial DNA and activity of mitochondrial enzymes in chronic active lesions of multiple sclerosis. J Neurol Sci 2000;177 : 95-103.

[124]. Linnik, M.D., Zobrist, R.H. and Hatceld, M.D. (1993) Stroke 24, 2002, 2008.

[125]. Luo, X., B. Reicheter, J. Trines et al. 1999. L-Carnitine attenuates doxorubicin induced lipid peroxidation in rats. J. Free Radicals Biol. Med. 26: 1158-1165.

[126]. Murray WJ, Reed KW, Roche EB. Conformations of carnitine and acetylcarnitine and the relationship to mitochondrial transport of fatty acids. J Theor Biol 1980; 82:559-572.

[127]. Maccari, F., A. Arseni, P. Chiodi et al. 1990. Levels of carnitines in brain and other tissues of rats of different ages: effect of acetyl-L-carnitine administration. Exp.Gerontol. 25: 127-134.

[128]. Maccari, F., Arseni, A., Chiodi, P., Ramacci, M. T. and Angelucci, L. (1990). Exp. Gerontol. 25:127-134.

[129]. Martha C. Mutombaa, Hua Yuana, Mary Konyavkoa, Souichi Adachia, Christopher B. Yokoyamaa, Victoria

Esserb, J. Denis McGarryb, Bernard M. Babiora, Roberta A. Gottlieba. Regulation of the activity of caspases by Lcarnitine and Palmitoylcarnitine. FEBS Letters 478, (2000), 19-25. 
[130]. McEwen ML, Sullivan PG, Rabchevsky AG, Springer JE (2011). Targeting mitochondrial function for the treatment of acute spinal cord injury. Neurotherapeutics 8: 168-179.

[131]. Malek Mahdavi A, Mahdavi R, Kolahi S.Effects of L-Carnitine Supplementation on Serum Inflammatory Factors and Matrix Metalloproteinase Enzymes in Females with Knee Osteoarthritis: A Randomized, Double-Blind, Placebo-Controlled Pilot Study. J Am Coll Nutr. 2016 Sep-Oct; 35(7):597-603.

[132]. Mariano Malaguarnera, Marco Vacante, Teresio Avitabile, Marcella Malaguarnera, Lisa Cammalleri, and Massimo Motta. L-Carnitine supplementation reduces oxidized LDL cholesterol in patients with diabetes. Am J Clin Nutr. 2009 Jan; 89 (1):71-76.

[133]. Mckay Hart, A., M. Wiberg and G. Terenghi. 2002. Pharmacological enhancement of peripheral nerve regeneration in the rat by systemic acetyl-L-carnitine treatment. Neurosci. Lett. 334: 181-185.

[134]. Montgomery, S.A., L.J. Thal and R. Amrein. 2003. Meta-analysis of double blind randomized controlled clinical trials of acetyl-L-carnitine versus placebo in the treatment of mild cognitive impairment and mild Alzheimer's disease. Int. Clin. Psychopharmacol. 18: 61-71.

[135]. Manfridi A, Forloni GL, Arrigoni-Martelli E, Mancia M (1992) Culture of dorsal root ganglion neurons from aged rats: effects of acetyl-L-carnitine and NGF. Int J Dev Neurosci 10: 321-329.

[136]. Mutomba MC, Yuan H, Konyavko M, Adachi S, Yokoyama CB, Esser V, McGarry JD, Babior BM, Gottlieb RA. Regulation of the activity of caspases by L-carnitine and palmitoylcarnitine. FEBS Lett. 2000 Jul 28; 478 (12):19-25.

[137]. Matera M, Bellinghieri G, Costantino G, SantoroD, Calvani M, Savica V. History of L-carnitine: Implications for renal disease. J Ren Nutr 2003; $13: 2-14$.

[138]. Mutomba MC, Yuan H, Konyavko M, Adachi S,Yokoyama CB, Esser V, McGarry JD, BabiorBM, Gottlieb RA. Regulation of the activity of caspases by L-carnitine and palmitoylcarnitine, FEBS Lett 2000; 478: 19-25.

[139]. Monti D, Troiano L, Tropea F, Grassilli E, Cossarizza A, Barozzi D, Pelloni MC, Tamassia MG, Bellomo G, Franceschi C. Apoptosis-programmed cell death: a role in the aging process? .Am J Clin Nutr. 1992; Jun, 55(6 Suppl):1208S-14S. Review.

[140]. Moretti S, Alesse E, Di Marzio L, Zazzeroni F, Ruggeri B, Marcellini S, Famularo G, Steinberg SM, Boschini A, Cifoe MG, De Simone C. Effect of L-carnitine on human immunodeficiency virus-1 infection-associated apoptosis: a pilot study. Blood. 1998; May 15, 91(10), 3817-24.

[141]. Mazzio E, Yoon KJ, Karam FA, Mazzio SE, Soliman KF. D-(+)-Acetyl-L-carnitine cytoprotection against 1methyl-4-phenylpyridinium toxicity in neuroblastoma cells. Biochem Pharmacol 2003; 66:297-306.

[142]. M. Bogdanov, R. H. Brown, W. Matson et al., "Increased oxidative damage to DNA in ALS patients," Free Radical Biology and Medicine, vol. 29, no. 7, pp. 652-658, 2000.

[143]. Nagaraja Haleagrahara, Cheng Jun Siew and Kumar Ponnusamy. "Effect of quercetin and desferrioxamine on 6-hydrocydopamine (6-OHDA) induced neurotoxicity in striatum of rats. J. Toxicol. Sci., Vol: 38, No: 1, 25-33, 2013. [144]. Orrell RW, Lane JM, Ross MA. Antioxidant treatment for amyotrophic lateral sclerosis / motor neuron disease. Cochrane Database Syst Rev 2005; 1: CD002829.

[145]. Plioplys AV, Bagherpour S, Kasnicka I. L-Carnitine as a treatment of lethargy in children with chronic neurologic handicaps. Brain Dev 1994; 16:146-149.

[146]. Plioplys AV, Plioplys S. Amantadine and L-carnitine treatment of chronic fatigue syndrome. Neuropsychobiology 1997; 35:16-23.

[147]. Paradies, G., Ruggiero, F. M., Petrosillo, G., Gadaleta, M. N. and Quagliariello, E. (1995) Mech. Ageing Dev. 84, 103-112.

[148]. Paradies, G., Ruggiero, F. M., Gadaleta, M. N. and Quagliariello, E. (1992). Biochim. Biophys. Acta, 1103:324-326.

[149]. Pettegrew JW, Levine J, McClure RJ (2000). Acetyl-L-carnitine physicalchemical, metabolic, and therapeutic properties: relevance for its mode of action in Alzheimer's disease and geriatric depression. Mol Psychiatry 5: 616632.

[150]. Paulson, D.J., A.L. Shug and J. Zhao. 1992. Protection of the ischemic diabetic heart by L-propionylcarnitine therapy. Mol. Cell. Biochem. 116: 131-137. 
Texila International Journal of Basic Medical Science

Volume 2, Issue 1, Jul 2017

[151]. Paulson DJ, Traxler J, Schmidt M, Noonan J, Shug AL. Protection of the ischaemic myocardium by Lpropionylcarnitine: effects on the recovery of cardiac output after ischaemia and reperfusion, carnitine transport, and fatty acid oxidation. Cardiovasc Res. 1986 Jul; 20(7):536-41.

[152]. Piero Ruggenenti, Dario Cattaneo, Giacomina Loriga, Franca Ledda, Nicola Motterlini, Giulia Gherardi, Silvia Orisio, Giuseppe Remuzzi. Ameliorating Hypertension and Insulin Resistance in Subjects at Increased Cardiovascular Risk: Effects of Acetyl-L-Carnitine Therapy. Hypertension. 2009; 54:567-574.

[153]. Paradies, G., F.M. Ruggiero and P. Dinoi. 1992. Decreased activity of the phosphate carrier and modification of lipids in cardiac mitochondria from senescent rats. Int. J. Biochem. 24: 783-787.

[154]. Paradies, G., F.M. Ruggiero, G. Petrosillo et al. 1994. Effect of aging and acetyl-Lcarnitine on the activity of cytochrome oxidase and adenine nucleotide translocase in rat heart mitochondria. FEBS Lett. 350: 213-215.

[155]. Paradies, G., G. Petrosillo, M.N. Gadeleta and F.M. Ruggiro. 1999. The effect of aging and acetyl-L-carnitine on the pyruvate transport and oxidation in rat heart mitochondria. FEBS Lett. 454: 207-209.

[156]. Pillich RT, Scarsella G, Risuleo G. Reduction of apoptosis through the mitochondrial pathway by the administration of acetyl-L-carnitine to mouse fibroblasts in culture. Exp Cell Res 2005; 306: 1-8.

[157]. P.Kumar, R.Sutha, G.Kavitha, K.Suresh Kanna A.Murugesan and S.Sreelatha, International Medical University, Kuala Lumpur, Malaysia, EPHAR 2008 Congress Abstract C002, Manchester, British Pharmacology Society (BPS) UK, 13-17 July 2008, Fundamental \& Clinical Pharmacology, Vol 22, Issue s2 (p 47-55), Aug 2008. [158]. Paradies, G., Ruggiero, F. M., Petrosillo, G., Gadaleta, M. N. and Quagliariello, E. (1994) FEBS Lett. 350, 213-215.

[159]. Qi SN, Zhang ZF, Wang ZY, Yoshida A, Ueda T. L-carnitine inhibits apoptotic DNA fragmentation induced by a new spin-labeled derivative of podophyllotoxin via caspase-3 in Raji cells. Oncol Rep 2006; 15: 119-22.

[160]. Rabchevsky AG, Patel SP, Springer JE (2011). Pharmacological interventions for spinal cord injury: where do we stand? How might we step forward? Pharmacol Ther 132: 15-29.

[161]. Rani, P.J. and C. Panneerselvam. 2002. Effect of L-carnitine on brain lipid peroxidation and antioxidant enzymes in old rats. J. Gerontol. Biol. Sci. Med. Sci. 57: B134-B137.

[162]. Rezenik, A.Z., V.E. Kagan, R. Ramsey et al. 1992. Antiradical effects in L-propionyl carnitine protection of the heart against ischemia-reperfusion injury: the possible role of iron chelation. Arch. Biochem. Biophys. 296: 394401.

[163]. Ruggenenti P, van der Meer IM, Remuzzi G. Oral acetyl-L-carnitine therapy and insulin resistance. Hypertension. 2010 Jun; 55(6):e26.

[164]. Rani, P.J. \& C. Panneerselvam. 2002. Effect of L-carnitine on brain lipid peroxidation and antioxidant enzymes in old rats. J. Gerontol. Biol. Sci. Med. Sci. 57: B134-B137.

[165]. Rahman A, Ustundag B, Burma O, Ozercan IH, Erol FS (2001). Neuroprotective effect of regional carnitine on spinal cord ischemia-reperfusion injury. Eur J Cardiothorac Surg 20: 65-70.

[166]. Rani PJ, Panneerselvam C (2002). Effect of L-carnitine on brain lipid peroxidation and antioxidant enzymes in old rats. J Gerontol A Biol Sci Med Sci 57:B134-B137.

[167]. R. J. Ferrante, S. E. Browne, L. A. Shinobu et al., "Evidence of increased oxidative damage in both sporadic and familial amyotrophic lateral sclerosis," Journal of Neurochemistry, vol. 69, no. 5, pp. 2064-2074, 1997.

[168]. Reznick AZ, Kagan VE, Ramsey R, Tsuchiya M, Khwaja S, Serbinova EA et al (1992). Antiradical effects in propionyl carnitine protection of the heart against ischemia-reperfusion injury: the possible role of iron chelation. Arch Biochem Biophys 296:394-401.

[169]. Rani PJ and Panneerselvam C (2002). Effect of L-carnitine on brain lipid peroxidation and antioxidant enzymes in old rats. J Gerontol A Biol Sci Med Sci 57:B134-B137.

[170]. Saunders CD. Parkinson's disease: a new hope. Boston MA: Harvard Health Publication; 2000.

[171]. Siliprandi N, Siliprandi D, Ciman M. Stimulation of oxidation of mitochondrial fatty acids and of acetate by acetylcarnitine. Biochem J 1965; 96: 777-780.

[172]. Solarska K, Lewińska A, Karowicz-Bilińska A, Bartosz G.The antioxidant properties of carnitine in vitro. Cell Mol Biol Lett 2010; 15: 90-97. 
[173]. Savica V, Santoro D, Mazzaglia G et al. L-carnitine infusions may suppress serum C-reactive protein and improve nutritional status in maintenance hemodialysis patients. J Ren Nutr 2005; 15: 225-230

[174]. Schinetti, M.L., D. Rossini, R. Greco and A. Bertelli. 1987. Protective action of acetylcarnitine on NADPHinduced lipid peroxidation of cardiac microsomes. Drugs Exp. Clin. Res. 13: 509-515.

[175]. Spagnoli, A., Lucca, U., Menasce, G., Bandera, L., Cizza, G., Forloni, G., Tettamanti, M., Frattura, L., Tiraboschi, P. and Comelli, M. (1991) Neurology 41, 1726-1732.

[176]. Salsoso R, Guzmán-Gutiérrez E, Arroyo P, Salomón C, Zambrano S, Ruiz-Armenta MV, Blanca AJ, Pardo F, Leiva A, Mate A, Sobrevia L, Vázquez CM. Reduced L-Carnitine Transport in Aortic Endothelial Cells from Spontaneously Hypertensive Rats. PLoS One. 2014 Feb 28; 9(2):e90339.

[177]. Sharman, E.H., N.D. Vaziri, Z. Ni et al. 2002. Reversal of biochemical and behavioral parameters of brain aging by melatonin and acetyl L-carnitine. Brain Res. 957: 223-230.

[178]. Scafidi S, Racz J, Hazelton J, McKenna MC, Fiskum G. Neuroprotection by acetyl-L-carnitine after traumatic injury to the immature rat brain. Dev Neurosci. 2010; 32 (5-6):480-7.

[179]. Samejima, K., and Earnshaw, W.C. (2005). Trashing the genome: the role of nucleases during apoptosis. Nat. Rev. Mol. Cell Biol. 6, 677-688.

[180]. Savitha S, Panneerselvam C. Carnitine and lipoic acid alleviates protein oxidation in heart mitochondria during aging process. Biogerontology 2006; 7: 101-109.

[181]. Singh RP, Sharad SKS. Free Radicals and Oxidative Stress in Neurodegenerative Diseases: Relevance of Dietary Antioxidants. Journal of the Indian Academy of Clinical Medicine 2004; 5:218-225.

[182]. Sleem M, Taye A, El-Moselhy MA, Mangoura SA. Combination therapy with losartan and L-carnitine protects against endothelial dysfunction of streptozotocin-induced diabetic rats. Eur J Pharmacol. 2014 Dec 5; 744:10-17.

[183]. Shug AL, Schmidt MJ, Golden GT, et al. The distribution and role of carnitine in the mammalian brain. Life Sci 1982; 31 (25):2869-2874.

[184]. Swerdlow RH, Golbe LI, Parks JK, et al. Mitochondrial dysfunction in cybrid lines expressing mitochondrial genes from patients with progressive supranuclear palsy. J Neurochem 2000; 75: 1681-1684.

[185]. Sener G, Eksioglu-Demiralp E, Cetiner M, Ercan F, Sirvanci S, Gedik N, et al. L-Carnitine ameliorates methotrexate-induced oxidative organ injury and inhibits leukocyte death. Cell Biol Toxicol 2006; 22: 47-60.

[186]. Teichert J, Kern J, Tritschler HJ, et al. Investigations on the pharmacokinetics of alpha-lipoic acid in healthy volunteers. Int J Clin Pharmacol Ther. 1998; 36:625-628.

[187]. Tamilselvan J, Jayaraman G, Sivarajan K, Panneerselvam C. Age-dependent upregulation of p53 and cytochrome $\mathrm{c}$ release and susceptibility to apoptosis in skeletal muscle fiber of aged rats: role of carnitine and lipoic acid. Free Radic Biol Med. 2007 Dec 15; 43(12):1656-69.

[188]. Tesco, G., S. Latorraca, P. Piersanti et al. 1992. Protection from oxygen radical damage in human diploid fibroblasts by acetyl-L-carnitine. Dementia 3: 58-60.

[189]. Thomsen, J.H., Shug, A.L., Yap, V.U., Patel, A.K., Karras, T.J. and DeFelice, S.L. (1979) Am. J. Cardiol. 43, 300-306.

[190]. Taglialatela, G., A. Caprioli, A. Giuliani and O. Ghirardi. 1996. Spatial memory and NGF levels in aged rats: natural variability and effects of acetyl-L-carnitine treatment. Exp. Gerontol. 31: 577-587.

[191]. Taglialatela G, Angelucci L, Ramacci MT, Werrbach-Perez K, Jackson GR, et al. (1991) Acetyl-L-carnitine enhances the response of PC12 cells to nerve growth factor. Brain Res Dev Brain Res 59: 221-230.

[192]. Takada G. Komatsu K, Goto R. Carnitine deficiency in lysinuric protein intolerance: lysine-sparing effect of carnitine. Tohoku J Exp Med.1987; Dec, 153 (4), 331-334.

[193]. Tomassini V, Pozzilli C, Onesti E, et al. Comparison of the effects of acetyl L-carnitine and amantadine for the treatment of fatigue in multiple sclerosis: results of a pilot, randomised, doubleblind, crossover trial. J Neurol Sci 2004; 218:103-108.

[194]. Tomassini V, Pozzilli C, Onesti E et al (2004). Comparison of the effects of acetyl-L-carnitine and amantadine for the treatment of fatigue in multiple sclerosis: results of a pilot, randomised, double-blind, crossover trial. J Neurol Sci 218:103-108. 
Texila International Journal of Basic Medical Science

Volume 2, Issue 1, Jul 2017

[195]. The Canadian MS Research Group. A randomized controlled trial of amantadine in fatigue associated with multiple sclerosis. Can J Neurol Sci 1987; 14(3):273-278.

[196]. Villa, R. F., Turpeenoja, L., Benzi, G. and Giuffrida Stella, A. M. (1998). Neurochem. Res. 10, 909-916.

[197]. Vernez L, Dickenmann M, Steiger J, Wenk M, Krähenbühl S. Effect of L-carnitine on the kinetics of carnitine, acylcarnitines and butyrobetaine in long-term haemodialysis. Nephrol Dial Transplant. 2006 Feb; 21(2):450-458.

[198]. Villa, R.F., L. Turpeenoja, G. Benzi \& A.M. Giuffrida Stella. 1998. Action of L-acetylcarnitine on agedependent modifications of mitochondrial membrane proteins from rat cerebellum. Neurochem. Res. 10: 909-916.

[199]. Vescovo G, Ravara B, Gobbo V, Sandri M,Angelini A, Della Barbera M, Dona M, Peluso G,Calvani M, Mosconi L, Dalla Libera L. L-carnitine: Apotential treatment for blocking apoptosis and preventing skeletal musclemyopathy in heart failure. Am J Physiol-Cell physiol 2002; 283: C802-C810.

[200]. Vanella, A., Russo, A., Acquaviva, R., Campisi, A., Di Giacomo, C., Sorrenti, V. and Barcellona, M.L. (2000). L-propionylcarnitine as superoxide scavenger, antioxidant and DNA cleavage protector. Cell Biol. Toxicol. , 16 (2): 99-104.

[201]. Vielhaber S, Kaufmann J, Kanowski M, et al. Effect of creatine supplementation on metabolite levels in ALS motor cortices. Exp Neurol 2001; 172: 377-382.

[202]. Vyshkina T, Banisor I, Shugart YY, et al. Genetic variants of complex I in multiple sclerosis. J Neurol Sci 2005; 228:55-64.

[203]. Wilson AD, Hart A, Brannstrom T, Wiberg M, Terenghi G. Primary sensory neuronal rescue with systemic acetyl-Lcarnitine following peripheral axotomy. A dose-response analysis. Br. J. Plast. Surg. 2003; 56: 732-739.

[204]. Waber, L.J., D. Valle, C. Neill et al. 1982. Carnitine deficiency presenting as familial cardiomyopathy: a treatable defect in carnitine transport. J. Pediatr. 101: 700-705.

[205]. Yuji Ueno, Masato Koike, Yoshiaki Shimada, Hideki Shimura, Kenichiro Hira, Ryota Tanaka, Yasuo Uchiyama, Nobutaka Hattori, and Takao Urabe. L-carnitine enhances axonal plasticity and improves white-matter lesions after chronic hypoperfusion in rat brain. J Cereb Blood Flow Metab. 2015 Mar; 35(3): 382-391.

[206]. Yamada, K. A., Kanter, E. M and Newatia, A. Long-chain acylcarnitine induces Ca2+ efflux from the sarcoplasmic reticulum. J Cardiovasc Pharmacol 36, 14-21, (2000).

[207]. Y. Ihara, K. Nobukuni, H. Takata, and T. Hayabara. "Oxidative stress and metal content in blood and cerebrospinal fluid of amyotrophic lateral sclerosis patients with and without a $\mathrm{Cu}, \mathrm{Zn}$-superoxide dismutase mutation," Neurological Research, vol. 27, no. 1, pp. 105-108, 2005.

[208]. Yongkang Dong, , Ling Zhang, Wenjiao Zhu, Hong Chu, Wei Fan, Liming Wu, Jianwei Shao, Weiliang Ding, Tieliang Ma. Modulation of age-associated oxidative DNA damage in rat brain cerebral cortex, striatum and hippocampus by 1-carnitine. Experimental Gerontology, 40, 3, 2005, 129-135

[209]. Yongkang Dong, Ling Zhang, Wenjiao Zhu, Hong Chu, Wei Fan, Liming Wu, Jianwei Shao, Weiliang Ding, Tieliang Ma. Effect of L-carnitine on DNA damage and oxidative stress in maintenance hemodialysis patients with hepatitis C virus infection in East China. Int J Clin Exp Med 2016; 9 (3):6100-6106.

[210]. White HL, Scates PW. Acetyl-L-carnitine as a precursor of acetylcholine. Neurochem Res1990; 15: 597-601.

[211]. Yasui, F., S. Matsugo, M. Ishibashi et al. 2002. Effects of chronic acetyl-L-carnitine treatment on brain lipid hydroperoxide level and passive avoidance learning in senescence-accelerated mice. Neurosci. Lett. 334: 177-180.

[212]. Yeun JY, Levine RA, Mantadilok V et al. C-reactive protein predicts all cause and cardiovascular mortality in hemodialysis patients. Am J Kidney Dis 2000; 35: 469-476

[213]. Yano T, Itoh Y, Yamada M, Egashira N, Oishi R. Combined treatment with L-carnitine and a pan-caspase inhibitor effectively reverses amiodarone-induced injury in cultured human lung epithelial cells. Apoptosis. 2008 Apr;13(4):543-52.

[214]. Zhou X, Liu F, Zhai S. Effect of L-carnitine and/or L-acetylcarnitine in nutrition treatment for male infertility: a systematic review. Asia Pac J Clin Nutr 2007; 16 Suppl 1: 383-90.

[215]. Zhang ZY, Fan ZK, Cao Y, Jia ZQ, Li G, Zhi XD, Yu DS, Lv G. Acetyl-L-carnitine ameliorates mitochondrial damage and apoptosis following spinal cord injury in rats. Neurosci Lett. 2015 Sep 14; 604: 18-23.

[216]. Zanelli SA, Solenski NJ, Rosenthal RE, Fiskum G. Mechanisms of ischemic neuroprotection by Acetyl-Lcarnitine. Ann N Y Acad Sci 2005; 1053: 153-161. 